\section{G员员區 \\ REPORT 89-23 \\ 89023776}

U.S. ARMY COLD REGIONS RESEARCH AI:D ENGINEERING LABORATORY ATTN: Library

72 Lyme Road Hanover, NH 03755

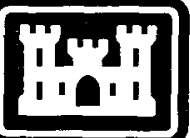

\section{US Army Corps} of Engineers

Cold Regions Research \& Engineering Laboratory

Thermal response of downhill skis

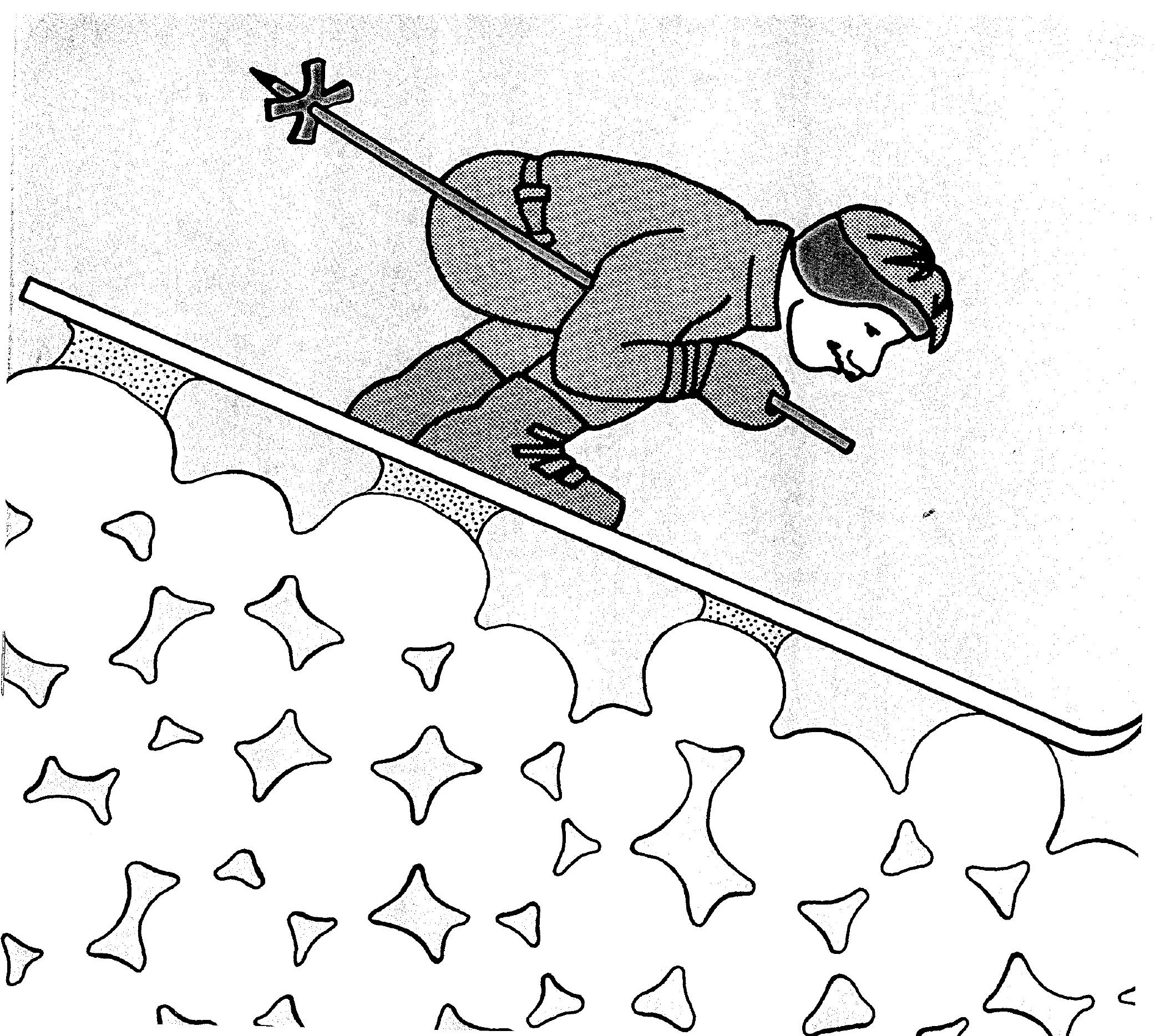




\section{CRREL Report 89-23}

December 1989

\section{Thermal response of downhill skis}

Guy C. Warren, Samuel C. Colbeck and Francis E. Kennedy 
UNCLASSIFIED

SECURITY CLASSIFICATION OF THIS PAGE

REPORT DOCUMENTATION PAGE

\begin{tabular}{|c|c|c|c|c|c|}
\hline $\begin{array}{l}\text { 1a. REPORT SECURITY CLASSIFICATION } \\
\text { Unclassified }\end{array}$ & & \multicolumn{4}{|c|}{ 1B. RESTRICTIVE MARKINGS } \\
\hline \multicolumn{2}{|l|}{ 2a. SECURITY CLASSIFICATION AUTHORITY } & \multicolumn{4}{|c|}{$\begin{array}{l}\text { 3. DISTRIBUTION/AVAILABILITY OF REPORT } \\
\text { Approved for public release; } \\
\text { distribution is unlimited. }\end{array}$} \\
\hline $\begin{array}{l}\text { 4. PERFORMING ORGANIZATION REPORT NUMBE } \\
\text { CRREL Report } 89-23\end{array}$ & & \multicolumn{4}{|c|}{ 5. MONITORING ORGANIZATION REPORT NUMBER(S) } \\
\hline $\begin{array}{l}\text { 6O. NAME OF PERFORMING ORGANIZATION } \\
\text { U.S. Army Cold Regions Research } \\
\text { and Engineering Laboratory }\end{array}$ & $\begin{array}{l}\text { 6b. OFFICE SYMBOL } \\
\text { (if applicable) } \\
\text { CECRL }\end{array}$ & \multicolumn{4}{|c|}{ 7O. NAME OF MONITORING ORGANIZATION } \\
\hline $\begin{array}{l}\text { 6c. ADDRESS (City, State, and ZIP code) } \\
72 \text { Lyme Road } \\
\text { Hamover, N.H. 03755-1290 }\end{array}$ & & 7b. ADDRESS & D.C. 20314- & & \\
\hline $\begin{array}{l}\text { 80. NAME OF FUNDING/SPONSORING } \\
\text { ORGANIZATION }\end{array}$ & $\begin{array}{l}\text { 8b. OFFICE SYMBOL } \\
\text { (if applicable) }\end{array}$ & \multicolumn{4}{|c|}{ 9. PROCUREMENT INSTRUMENT IDENTIFICATION NUMBER } \\
\hline \multirow{2}{*}{\multicolumn{2}{|c|}{ 8c. ADDRESS (City, State, and ZIP Code) }} & \multicolumn{4}{|c|}{ 10. SOURCE OF FUNDING NUMBERS } \\
\hline & & $\begin{array}{l}\text { PROGRAM } \\
\text { ELEMENT NO. }\end{array}$ & $\begin{array}{l}\text { PROJECT } \\
\text { NO. } 4 \text { B } 1611 \\
\text { O2AT24 }\end{array}$ & $\begin{array}{l}\text { TASK } \\
\text { NO. }\end{array}$ & $\begin{array}{l}\text { WORK UNIT } \\
\text { ACCESSION NO. }\end{array}$ \\
\hline
\end{tabular}

11. TITLE (Include Securify Classification)

Thermal Response of Downhill Skis

12. PERSONAL AUTHOR(S)

Warren, Guy C., Colbeck, Samuel C. and Kennedy, Francis E.

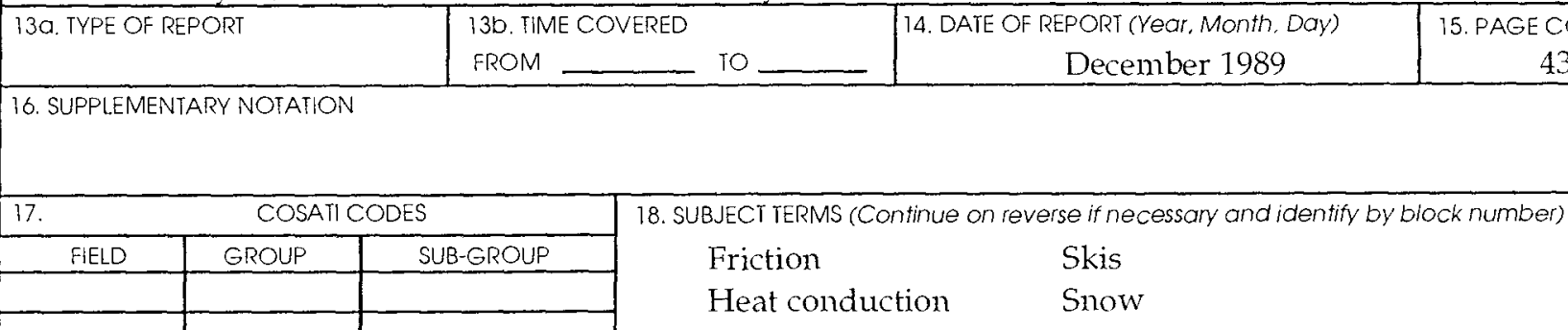

19. ABSIRACT (Continue on reverse if necessary and identify by block number)

Large temperature increases were measured in downhill skis. A steady-state temperature was observed at the base, indicating that melting occurs over some portion of the base. This steady-state temperature increases with the ambient temperature and depends on ski speed and load, and the type of snow on the surface. Heat was observed to propagate up through the ski in both the field measurements and in a finite element model of a Rossignol DH ski. In that particular ski, much heat propagates along an aluminum plate that comnects with the steel edges of the ski. This combination about doubles the heat loss from the base and could reduce the thickness of the layer of lubricating meltwater, especially at lower temperatures. These large temperature increases provide further evidence of the existence of a layer of meltwater that would control the friction. The finite element model allows the predictions of material properties and geometry in the design of sliders for snow and ice.

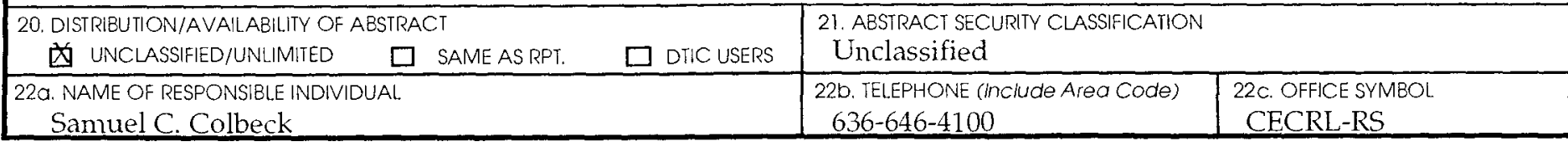




\section{PREFACE}

This report was prepared by Guy C. Warren, Graduate Student, Thayer School of Engineering, Dartmouth College, Dr. Samuel C. Colbeck, Research Geophysicist, Snow and Ice Branch, U.S. Army Cold Regions Research and Engineering Laboratory, and Francis E. Kennedy, Professor of Engineering, Thayer School of Engineering, Dartmouth College. Funding for this research was provided by DA Project 4B161102A T24, Plysical Propertics of Snowend loe.

K. Jones and Dr. J.-C. Tatinclatux of CRREL technically reviewed the manuscript of this report. The authors thank Rossignol for providing the $\mathrm{DH}$ ski and Salomon for providing the bindings.

The contents of this report are not to be used for advertising or promotional purposes. Citation of brand names does not constitute an official endorsement or approval of the use of such commercial products. 


\section{CONTENTS}

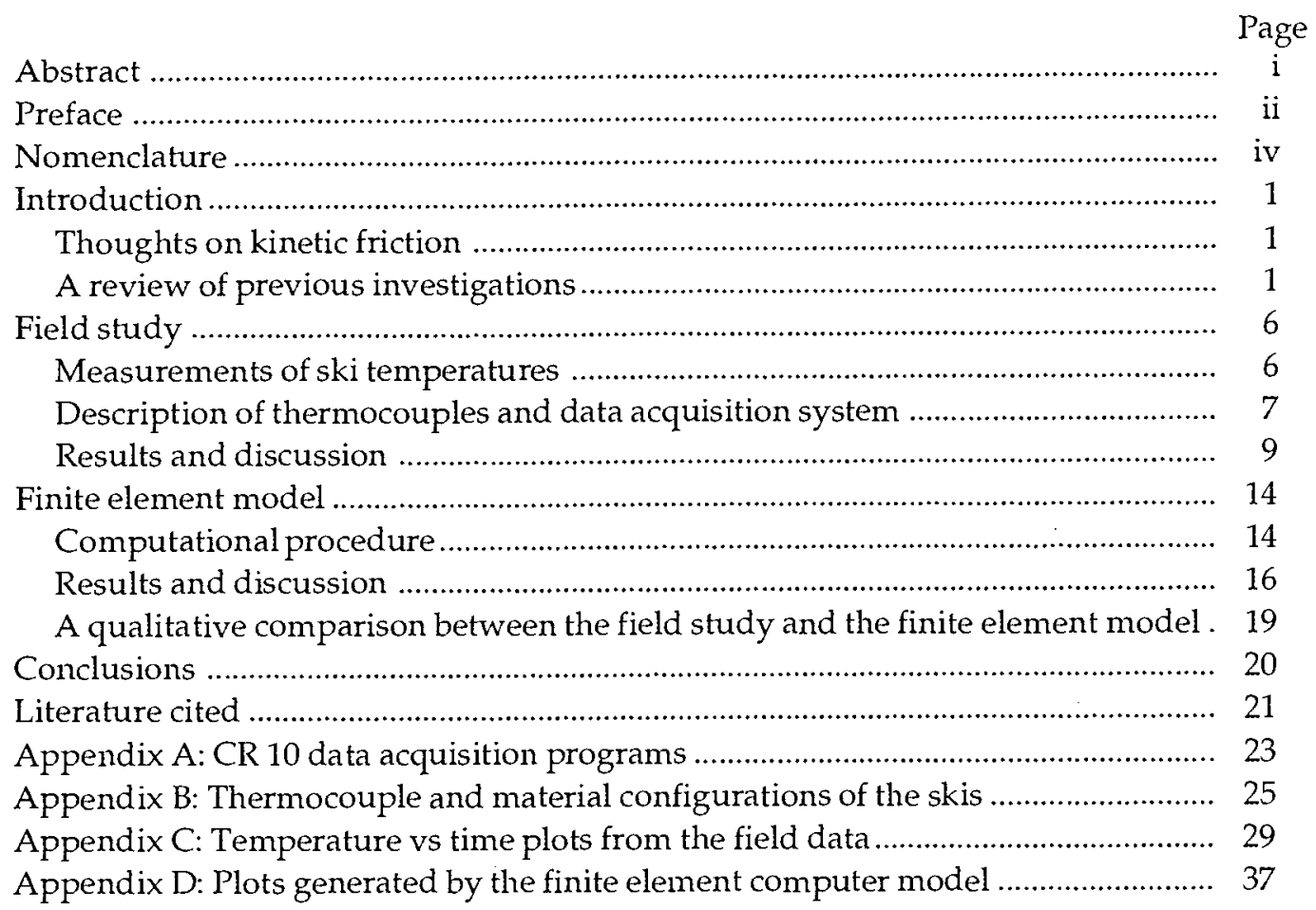

\section{ILLUSTRATIONS}

Figure

1. Crystal from snow surface with melt cap ………….............................................. 2

2. Wiring configuration between data logger and multiplexer ................................ 7

3. Steady-state versus ambient temperature for the Blitz ski ................................ 10

4. Independence of velocity and steady-state temperature for the Blitz ski........... 10

5. Heat flow constant vs ambient temperature for the Blitz ski .............................. 10

6. Temperature rise vs load for the Blitz ski ...........................................................

7. Temperature rise vs transverse position for two snow types.............................. 11

8. Temperature rise vs longitudinal position for different snow types ................... 12

9. Pressure vs distance from front of DH ski ...................................................... 12

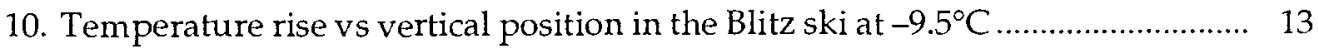

11. Temperature rise vs vertical position in the $\mathrm{DH}$ ski at $-1.8^{\circ} \mathrm{C} \ldots \ldots \ldots \ldots \ldots \ldots \ldots \ldots \ldots . . . . . . . . . . .13$

12. Finite element mesh with node numbers ….................................................. 15

13. Temperature rise at node 46 vs time for case 1 ............................................... 17

14. Computed vertical temperature profile for nodes $110,76,58$ and $40 \ldots \ldots \ldots \ldots \ldots \ldots . . .17$

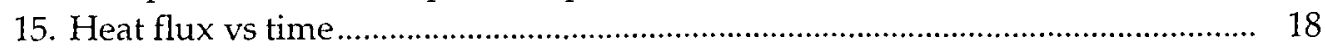

16. Steady-state temperature distribution ............................................................. 19

\section{TABLE}

1. Thermal properties of materials in DH ski ........................................................ 16 


\section{NOMENCLATURE}

$A$ Constant depending on area, geometry and surface nature of slider

$a, b$ Contact dimensions

c Ratio of area to weight of slider

$f$ Frictional force

$F_{\mathrm{i}} \quad$ Force analogous to heat conducted into ice

$F_{\mathrm{m}} \quad$ Force analogous to heat required to melt surface of ice

$F_{s} \quad$ Force analogous to heat conducted into slider

$H$ Convection coefficient

$h$ Thickness of mel twater film

$k$ Thermal conductivity

$L \quad$ Latent heat of fusion

$N$ Load on slider

$n$ Geometrical factor

Q Rate of heat generation

$q$ Heat flux

$r$ Radius of contacts

$R \quad$ Heat flow ratio

$T_{\mathrm{m}} \quad$ Melting temperature

$T_{0} \quad$ Ambient temperature

$t$ Time

$v$ Velocity

$\kappa \quad$ Thermal diffusivity

$\mu \quad$ Coefficient of kinetic friction

$\mu_{\mathrm{m}} \quad$ Energy dissipated by melting

$\eta \quad$ Dynamic viscosity of water

$\rho$ Density

Subscripts:

$i$ Ice or snow

$m \quad$ Melting

$s$ Slider

w Water 


\title{
Thermal Response of Downhill Skis
}

\author{
GUY C. WARREN , SAMUEL C. COLBECK AND FRANCIS E. KENNEDY
}

\section{INTRODUCTION}

The low friction of snow and ice has long been recognized as one of the distinguishing characteristics of the cold regions. The low friction is thought to result from the frictional heating produced by the slider. The heat generated appears to create a thin meltwater layer that provides lubrication and reduces the area of solid-to-solid contact between the snow and the gliding surface of the slider. The amount of heat generated at the frictional interface accounts for more than $95 \%$ of all the frictional energy losses, and is very sensitive to the ambient conditions. The propagation of this heat from the frictional interface should depend on both the ambient temperature and the thermal characteristics of the slider. Using both field measurements and a finite element model, we will show that the thermal characteristics of downhill skis have a significant effect on the temperature at the ski base. Other sliders should have similar responses.

Before we describe the temperature fields in skis, we review some of what is already known about snow and ice friction and then look at some of the most important work done to da te. Then the results of both field measurements and finite element simulations will be given.

\section{Thoughts on kinetic friction}

In an effort to optimize sliding on snow, it is important to have an understanding of the dissipative nature of friction. The coefficient of kinetic friction is defined as the ratio of the frictional force $f$ to the normal force $N$ and is referred to as Amonton's Law. When two surfaces rub together, the mechanical energy loss is dissipated in a number of forms, including noise and heat. Heat is the dominant mode of dissipation, so its rate $Q$ is given approximately by the product of the coefficient of kinetic friction $\mu$, the rela tive speed $"$ between the interactive materials, and the normal force $N$, or

$$
Q=\mu \nu N=i f .
$$

Under some conditions, this heat production can cause melting of one or both of the materials at the frictional interface; in fact, frictional melting is of interest for a variety of materials, not just snow and ice. When melting occurs, the resulting liquid acts as a lubricant that reduces the area of solid-tosolid contact between the two surfaces. The reduction in friction at the interface is primarily dependent on the thickness and viscosity of this liquid layer. According to the theory of Colbeck (1988), when an object slides over snow, the sliding action between the slider and the snow can result in melting of the snow and the introduction of a layer of meltwater that reduces the kinetic friction at the interface. The meltwater can be sustained at the interface just by the heat generated from the shearing of the water. Thus, the sliding energy is used in a process that minimizes the friction.

There appears to be a number of parameters that affect the rate of heatgeneration at the interface. While the speed is more or less imposed, the frictional force is influenced by a number of parameters, including the ambient temperature, snow type and the thermal conductivity and surface characteristics of the slider. Controlled measuremen ts of the interface temperature would provide a test of the extent to which these parameters affect the thermal response and therefore the sliding resistance of materials on snow.

\section{A review of previous investigations}

The idea that a meltwater layer is responsible for the low friction of snow and ice has not always been accepted. A study of existing theories reveals that, although a majority of the previous investigators were proponents of the meltwater theory, 
one investigator argues that alternative processes other than meltwater lubrication might be responsible for the low friction observed. The previous work is worth looking at in some detail.

\section{Bowden and Hughes (1939)}

This study laid the found ation for much future work on ski and snow friction. Bowden and Hughes' investigation was primarily concerned with the frictional characteristics of ice, although the results apply, at least qualitatively, to snow as well. They showed that frictional heating, not pressure melting, is the cause of melting of the snow surface. This conclusion is easily demonstrated by calculating the depression of the melting temperature from the applied pressure for either ice skates or skis. Their calculation, however, was made under the assumption that the en tire base of the ski was in contact with the snow. The real area of contact has been estimated by Kuroiwa (1977) as $3.8 \%$ of the apparent area of contact. If this estimate is accurate, the ambient snow temperature would still have to be above $-0.004^{\circ} \mathrm{C}$ to allow pressure melting of the snow at the ski/snow interface. Bowden and Hughes also suggested that pressure melting could not be responsible for the low friction observed because the static and kinetic frictional coefficients differ greatly.

The frictional heat is concentrated at the points of contact and, although much of this heat is lost by conduction into the surrounding ice and ski, a sufficient amount can be retained to cause local melting of the snow crystals at the contact points. This is illustrated in Figure 1, which shows a meltcap on a snow grain that was removed by us from a snow surface after a slider passed over it.

Making further rough calculations, Bowden and

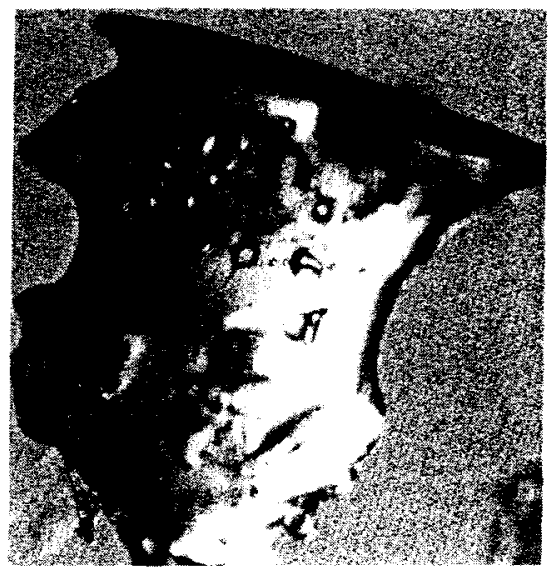

Figure 1. Crystal from snow surface with melt cap $\left(T=-4^{\circ} \mathrm{C}\right)$.
Hughes determined that sufficient frictional heat is generated during skiing to raise the temperature of the interface from -20 to $0^{\circ} \mathrm{C}$ and that the meltwater layer thickness at this ambient temperature is $55 \mu \mathrm{m}$ for a real contact area of $10 \mathrm{~mm}^{2}$. They also concluded that the extent of melting is dependent on the ambient temperature. At very low temperatures, insufficient heat is generated tocause melting and snow exhibits the same frictional characteristics as other unlubricated materials. One important point that Bowden and Hughes did not discuss is that, although insufficient heat is generated to initiate melting at these low temperatures, the amount of heat generated is far greater because of the higher friction that exists in the absence of a thin meltwater layer.

In their study they directly measured the coefficient of kinetic friction by placing a small slider on an ice-covered turntable. When the turntable was set in motion, they were able to measure the frictional force by recording the deflection of a spring. With this method, they made the following qualitative observations: Over a certain range of loads, the coefficient of kinetic friction remained constant, but at extremely heavy loads, the coefficient of kinetic friction decreased. This was a departure from Amonton's law but, according to Bowden and Hughes, can be attributed to the thick meltwater layer. They suggested that the presence of a thick meltwater layer increased the friction, due to viscous shear and surface tension, but that the coefficient of kinetic friction was unaffected by a change in the apparent area of contact. Bowden and Hughes hypothesized that speed influenced only the temperature increase of the slider and not the temperature increase of the snow. They attributed this to a slider continuously receiving heat during sliding, while a section of snow only received heat while the slider passed over it.

Bowden and Hughes drew some very interesting conclusions about the effect of the thermal conductivity of the slider on the coefficient of kinetic friction. The most obvious was that a slider of poor thermal conductivity would facilitate moremelting because of the greater retention of heat at the frictional interface. The effect of thermal conductivity on melting was thought to be more pronounced at lower temperatures. In an effort to determine the amount of melting occurring as a result of frictional heating, they investigated the electrical conductivity between the two counter surfaces at temperatures close to $0^{\circ} \mathrm{C}$. They discovered that the electrical conductivity increased as the slider was set in motion, suggesting the formation of a 
continuous meltwater layer. At lower temperatures, though, they observed smaller values of the electrical conductivity, suggesting that the meltwater layer was not continuous (i.e., melting occurred at localized points). Bowden and Hughes also observed the effect of waxes on the bases of skis and found that the substitution of a hydrophobic surface for a hydrophilic surface reduced the kinetic friction. This may be attributable to a reduction in surface tension, but an exact mechanism was not proposed. In any case, the result reaffirmed the theory of the meltwater layer.

Although most of their conclusions were based on the interaction between certain materials and ice, they did a few experiments using snow as the underlying material. They concluded that the general behavior was very similar to that observed on ice, except that the friction was always higher on snow. This, they remarked, was ascribable to the extra mechanical work required to deform the snow surface. Although many assumptions were made in their analysis, the results they obtained were, at least qualitatively, significant.

\section{Klein (1947)}

Klein studied the sliding resistance of aircraft skis. Although the skis used in his investigation were considerably larger in size and unit loading (load/total area), his experimental observations were almost identical to those of Bowden and Hughes. Klein explained his results in terms of the meltwater lubrication theory. He suggested that the layer of water under the ski was not of uniform thickness, and that at the front of the ski, which first came into contact with the undisturbed snow, the surface was dry.

Klein proposed that three types of sliding resistance existed at the base of a ski: solid friction at the front of the slider, viscous resistance due to shearing of the meltwater layer and surface tension effects. Each component would depend on the temperature, snow structure, unit loading and material in contact with the snow. Klein assumed the existence of solid-to-solid friction at the front of the ski through evidence of wear, which he noticed only occurred at the front of the ski.

He also made observations of the real area of contact. Previous values had only been estimated, but observations of water droplets in contact with the ski yielded values of 20 and $50 \%$ real contact areas at unit loadings of $1.38 \times 10^{6} \mathrm{~Pa}\left(200 \mathrm{lb} / \mathrm{ft}^{2}\right)$ and $3.45 \times 10^{6} \mathrm{~Pa}\left(500 \mathrm{lb} / \mathrm{ft}^{2}\right)$ respectively. If these values are accurate, for a pressure of $4.14 \times 10^{4} \mathrm{~Pa}$ $\left(60 \mathrm{lb} / \mathrm{ft}^{2}\right)$ (a common value for a skier), a $6 \%$ real contact area might be assumed. This is comparable to the estimate made by Kuroiwa (1977). However, Klein did not state under what conditions these observations were made, and the amount of meltwater at the base of the ski depends on the ambient conditions and the thermal characteristics of the slider.

\section{Ericksson (1949)}

Ericksson described the effects of snow type on the coefficient of friction of skis and concluded that the friction decreased as the snow grain size increased. The real area of contact may have been sensitive to the grain size, particularly if the size of the asperities on the gliding surface of the slider was comparable to the dimensions of the snow grains. This result supports the observation that skis run faster on snow that had undergone metamorphosis (i.e., an increase in grain size). This grain size effect is explained by Colbeck (1988) in terms of the dynamics of the water film.

\section{McConica (1950)}

McConica rejected the theory of meltwater lubrication and proposed that the low friction on snow was attributable to the adsorption of monolayers of water vapor that prevent adhesion, and thus decrease the resistance to starting. This theory was proposed as a result of a study of the "dry slipperiness" of graphite and magnesium. These materials produce, under pressure, plate-like crystals during atmospheric exposure that result in vaporfilm lubrication during sliding. Although this theory indicated that another form of lubrication might control the basal friction, McConica agreed that ski geometry and composition, temperature and condition of the snow, speed and loading affected the sliding resistance.

McConica employed the same experimental procedure as Bowden and Hughes, but performed his tests with a greater degree of control over the parameters aforementioned. Although the majority of his conclusions were based on theoretical calculations, the experiments that he conducted did yield some interesting results. He discovered that a magnesium (highly conductive) ski had a lower resistance to sliding than a well-lacquered wood (poorly conductive) skiat temperatures well below the melting point of the snow. Further, heat transmission calculations he made showed that the formation of a meltwater layer at these temperatures was doubtful. He believed this suggested that the retention of heat at the base of the ski did not influence the coefficient of kinetic friction and that 
the low friction observed must have been due to some other lubricating mechanism. McConica predicted that the base of the ski could not be at any temperature other than the ambient temperature of the snow when the ski was in motion. As shown later, this idea is certainly incorrect and leads us to question his other conclusions.

McConica's vapor theory was supported by the fact that magnesium is a hydrophilic material, which would create greater surface tension than a hydrophobic material (like lacquered wood) in the presence of a meltwater layer. In addition, a comparison between magnesium and aluminum showed that the magnesium ski had a lower coefficient of kinetic friction under all conditions because the film that forms on aluminum is amorphous and is not susceptible to vapor film lubrication: These resultss hould be tested further, especially in view of magnesium's chemical reactivity with water: Additional observations by McConica suggested that kinetic friction decreased as load increased, and kinetic friction decreased as speed increased.

\section{Bowden (1953)}

Bowden conducted tests with real snow skis to determine the effect of skibase finish, temperature, speed and snow hardness on friction. He determined that as the speed increased, the coefficient of friction was reduced because of the increase in melting. Also, as the temperature decreased, the coefficient increased because of the lack of melting. According to Bowden, a coating of Teflon on the base of the slider resulted in lower friction than any waxed base. This, he concluded, was ascribable to the high hydrophobicity of Teflon. In tests using waxes as a base material, he found that the snow was capable of penetrating the wax layer, resulting in a higher coefficient of friction than for the harder Teflon.

Bowden's study further supported his theory that localized surface melting, caused by frictional heating, was responsible for the low friction of sliders on snow. His analysis of the hydrophobicity of certain materials also explained the extent to which surface tension affected the ability of a ski to move forward in "wet" conditions.

\section{Tusima and Yosida (1969)}

The experimental study carried out by Tusima and Yosida best replicated real skiing conditions. Most previous experiments slid a ski on a moving turntable, which allowed the ski to pass over the same section of snow for an indefinite period. This accumulation of heat in both the ski and the snow would certainly increase the likelihood of meltwater formation. In the case of real skiing, the snow is always renewed, which limits the extent to which the snow surface could be heated.

Applying this experimental technique, Tusina and Yosida discovered that melting began as soon as forward motion began, but that the rate of melting reached a constant value with time. They theorized that the points of contact were at $0^{\circ} \mathrm{C}$ after only 0.1 seconds of forward motion and from their experiments determined that the water film thickness was between 10 and $50 \mu \mathrm{m}$. This range of values of the thickness was lower than those estimated by Bowden and Hughes, possibly because of the different experimental procedures used.

\section{Evans, Nye and Cheeseman (1976)}

Although Evans et al. were primarily interested in the kinetic friction of ice, they were the first investigators to use thermocouples in their analysis of temperature rises associated with frictional heating involving ice or snow. The measurements they made enabled them to predict the effect of slider thermal conductivity on friction. They found that for a copper slider, between 40 and $60 \%$ of the heat generated at the frictional interface was conducted away through the copper and that this fraction was apparently independent of the air temperature between -2 and $-15^{\circ} \mathrm{C}$. In addition, the heat conduction through the slider depended on the speed.

In determining the coefficient of friction, they made an analogy between the heat generated and the frictional force. They defined the total frictional force at the contact points as

$$
f=F_{\mathrm{s}}+F_{\mathrm{i}}+F_{\mathrm{m}}
$$

where $F_{\mathrm{s}}=$ force analogous to the heat conducted into the slider

$F_{\mathrm{i}}=$ force analogous to the heat diffused into the ice

$F_{m}=$ force analogous to the heat required to melt the surface of the ice.

According to Evans et al.

$$
F_{\mathrm{s}}=\frac{A k_{\mathrm{s}}\left(T_{\mathrm{m}}-T_{0}\right)}{v}
$$

where $A=$ constant that is dependent on the contact area, geometry and surface nature of the slider 
$k_{\mathrm{s}}=$ thermal conductivity of the slider

$T_{\mathrm{m}}^{\mathrm{s}}=$ melting temperature

$T_{0}=$ ambient temperature of the ice

$v=$ relative speed between the slider and the ice.

Also, they derived the force analogous to the heat diffused into the ice as

$$
F_{\mathrm{i}}=2 k_{\mathrm{i}}\left(T_{\mathrm{m}}-T_{0}\right) b(a / \pi \kappa v)^{1 / 2}
$$

where $k_{\mathrm{i}}=$ thermal conductivity of the ice

$$
\begin{aligned}
& a=\text { length of contact points } \\
& b=\text { width of contact points } \\
& \kappa=\text { thermal diffusivity. }
\end{aligned}
$$

Putting these two expressions together with eq 1 , the coefficient of friction becomes

$$
\mu=\frac{A k_{\mathrm{s}}\left(T_{\mathrm{m}}-T_{0}\right)}{v N}+\frac{1.74 k_{\mathrm{i}}\left(T_{\mathrm{m}}-T_{0}\right) b a 0.5}{N(\tau \kappa v)^{0.5}}+\mu_{\mathrm{m}}
$$

where $\mu_{\mathrm{m}}$ represents the energy dissipated by melting.

According to Evans et al., although $\mu_{\mathrm{m}}$ increased with $T_{0}$ it makes a small contribution to the total friction and could often be neglected. From eq 5 , we see that the coefficient of friction depends on the thermal conductivity of the slider and the ice, the area and geometry of the contact points, the ambient and melting temperature of the ice, the diffusivity of the ice, the load applied, and the speed of the slider. Comparing the values of friction obtained in their experiments with the values calculated by eq 5 , they found that the values agreed within a factor of two. The discrepancy, they concluded, was attributable to an overestimation of the real contact area.

\section{Ambach and Mayr (1981)}

Ambach and Mayr were able to determine the thickness of the meltwater layer by measuring the capacitance at the slider/snow interface. Their measurements were made at speeds approaching $60 \mathrm{~km} / \mathrm{hr}$ (approximately $17 \mathrm{~m} / \mathrm{s}$ ) and they found that the thickness of the water layer varied with speed, snow type, snow and air temperature, and the gliding ski surface. They concluded that the meltwater layer in skiing was 5 to $10 \mu \mathrm{m}$ thick and that its value increased with an increase in both the snow and air temperature, and with an increase in speed. In determining the effect of snow type, they used packed snow and deep, unpacked snow and found that the meltwater layer thickness was greater in the deep snow. They suggested that the reason for this was that on normal ski terrain, the snow surface was bumpy so heat generation was intermittent. Although Ambach and Mayr did not know the specific characteristics of the waxes they applied to the base of their test skis, they discovered that the meltwater thickness was larger for waxes whose temperature ranges included the ambient temperature of their tests. This indicated that an appropriate waxappeared to increase the thickness of the meltwater layer, resulting in a lower coefficient of kinetic friction.

\section{Oksanen (1983)}

Oksanen studied the friction and adhesion strength of ice. They measured the coefficients of both static and kinetic friction between ice and several materials as a function of load, speed and temperature. The apparatus used in thisstudy was a modified version of a turntable that Keinonen had used in his study of friction between skis and snow.

Oksanen predicted that at low temperatures (less than $-10^{\circ} \mathrm{C}$ ), the coefficient of kinetic friction would vary as $v^{-1 / 2}$, where $v$ is the relative speed between the material and the ice. This, he theorized, was ascribable to the self-balancing of the thin water layer. According to Oksanen, if the thickness of the meltwater layer decreased, the increased frictional heating would create more water, and if the meltwater layer thickness increased, the reduction in frictional heating would cause a dropin temperature at the contact below the melting point of the water. So at equilibrium, the temperature at the contact surface was at the melting point of water and the heat produced by the friction was equal to the heat conducted into the two solids. At higher temperatures (close to $0^{\circ} \mathrm{C}$ ), Oksanen determined that his equations reduced to a form that showed that the friction was determined by the viscous shear and increased as $v^{-1 / 2}$. His experimental results concerning the coefficient of kinetic friction supported his theory to a good approximation. The discrepancies, he concluded, were due to the assumption that viscous shearing was the only component of friction when a meltwater layer was present.

\section{Akkok, Ettles and Calabrese (1987)}

Akkok et al. developed a theory that suggested that the heat generated at the frictional interface at $-20^{\circ} \mathrm{C}$ was sufficient to raise the temperature of the interface by $40^{\circ} \mathrm{C}$. They contested that this rise in 
temperature was not realistic because any water that formed at the contact points was immediately removed by the motion of the slider. In light of this, they suggested that the interface could not attain a value any higher than $0^{\circ} \mathrm{C}$ and that the friction must be dependent on the ambient snow temperature. From their analytical model, they also suggested that the coefficient of kinetic friction depended on the load, speed and thermal characteristics of the slider. In addition, Akkok et al. were able to predict the thickness of the meltwater layer and obtained values that were comparatively small. They predicted a thickness of only a few micrometers, and said that the surface roughness of the slider prevented any hydrodynamic effects.

\section{Colbeck (1988)}

Colbeck developed a theory that predicts the heat generation by an object sliding on snow, the thickness of the resulting meltwater layer, and the effects of temperature, slider thermal conductivity, speed and snow type on the coefficient of kinetic friction. This theory was developed to describe the intermediate values of the meltwater layer thickness where the viscous effects of the meltwater film dominate frictional forces arising from solidto-solid ploughing or surface tension forces. From the mechanisms controlling the lubricated component of friction $\mu_{w}$ at the melting temperature, Colbeck found that

$$
\mu_{w}=\frac{c v \eta}{h}
$$

where $c$ is the ratio of area to the weight of the slider, and $h$ is the thickness of the water film. In addition, Colbeck calculated the square of the thickness of the water film to be

$$
h^{2}=\frac{\pi \eta v r}{\rho_{\mathrm{w}} L}
$$

where $r=$ radius of the water film

$$
\begin{aligned}
\rho_{w} & =\text { density of water at } 0^{\circ} \mathrm{C} \\
L & =\text { latent heat of fusion. }
\end{aligned}
$$

According to Colbeck, this implied that even in fairly icy conditions, the thickness of the meltwater layer never exceeded about $2 \mu \mathrm{m}$ in snow skiing. The discrepancy between this value and the values obtained by previous investigators may have been caused by the different effects of hydrophobic and hydrophilic surfaces. His analysis further suggested that $r$ increased with repeated passes. If this is true, then from eq 6 and 7, the coefficient of lubricating friction is reduced as $r$ increases, as Ericksson (1949) observed.

Colbeck also predicted values of the kinetic friction when the ambient temperature was below the melting temperature of the snow. It appeared that the thermal characteristics of the slider and snow greatly affected the friction. At lower temperatures, the dry friction component was larger than the lubricated component because of insufficient melting. Calculations of the heat generated by the dry friction suggested that the front of the slider was dry over a certain length. At the end of this dry portion, the water layer increased in thickness towards an equilibrium value. The length of the dry section was dependent on the temperature and the slider material.

Colbeck also concluded that the lubricated friction increased with $v^{1 / 2}$ at the melting temperature. However, at lower temperatures, this component of friction decreased before increasing with $v^{1 / 2}$ at higher speeds. In addition, Colbeck concluded that the thickness of the meltwater layer was highly dependent on the size of the contacts, speed, temperature and thermal characteristics of the slider, but was independent of the load applied. Unfortunately, many assumptions were necessary in these predictions.

Since much of our knowledge of snow and ice friction is based on theory, it is important to make measurements that provide direct information about the processes responsible for the low friction. While indirect measurements of the meltwater have been made, direct measurements of the temperature field have not. Thus, we measured temperatures to examine the heat generation and heat flow characteristics of downhill skis. We also generated solutions for the temperature field using the finite element technique to show that the heat flow characteristics of downhill skis can be simulated. This is necessary to show how the construction of skis affects their heat flow characteristics, and, therefore, their frictional behavior.

\section{FIELD STUDY}

\section{Measurements of ski temperatures}

To test some of the ideas given above it is very desirable to measure the temperature of the actual contact points between a slider and the snow, but limitations on thermocouple size and response 
times restrict us to measurements of the bulk temperature of the slider. However, if the contact points are at the melting temperature, as has been suggested many times, heat flow patterns up through a ski may indicate the extent of melting at the frictional interface.

From the previous investigations, the heat generated by friction appears to depend on the speed and thermal characteristics of the slider, the load applied to the slider, the ambient temperature of the snow and the snow type. Although our ability to control or even measure these parameters was rather limited in the tests described below, we felt that more information could be gained from the higher speeds and natural snow conditions found in skiing rather than on a laboratory test track. The highest speeds attained in these tests were about $18 \mathrm{~m} / \mathrm{s}$.

The objective is to measure the temperature rises in skis attributable to frictional heating. If the amount of heat generated is measurable, it might be possible to analyze the effects of various parameters on kinetic friction. These parameters includespeed, load, snow type, ambient temperature, and slider geometry and thermal conductivity. In addition, measurements of the temperature distribution in the ski might help in determining the materials that would be best at decreasing friction.

In developing an approach to these measurements, we decided that thermocouples installed in a downhill ski could be used to calculate the frictional heat generated at the base and the ensuing heat propagation in the ski. The thermocouples implanted were small so that significant changes in the structure of the ski could be avoided and so that the time response of the thermocouples would be short. Two skis were selected for instrumentation: a Blitz child'sski and a RossignolDH downhill racing ski. In the Blitzski, the thermocouples were implanted by boring a hole just wide enough for them to slide into their specified locations. Then the holes were back-filled with an epoxy resin to secure the thermocouples in place, strengthen the ski and minimize erroneous heat flow effects. The DH ski was built at the factory, where the thermocouples were installed during construction.

\section{Description of thermocouples and data acquisition system}

It was essential to employ a data acquisition system that was both durable and portable to measure the interfacial temperature increases duringskiing. In view of this, one of thesmall, computer

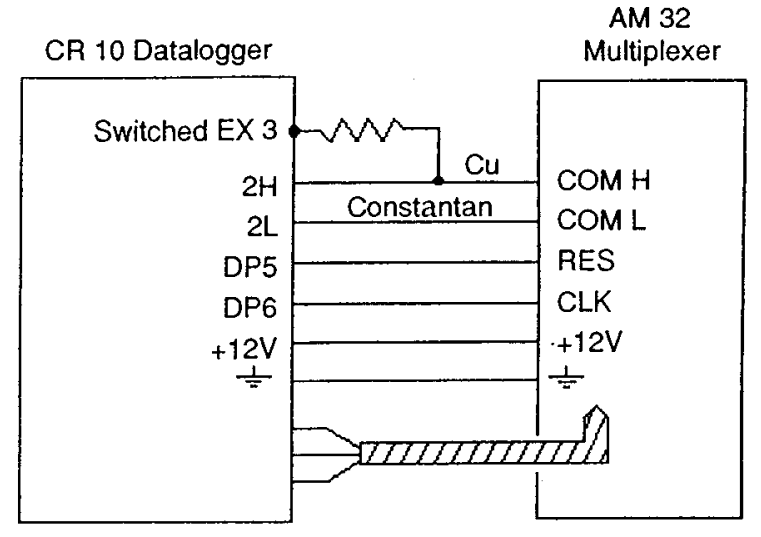

Figure 2. Wiring configuration between data logger and multiplexer.

controlled data loggers was chosen. The CR 10 was compact enough to be carried by a skier in a backpack and rugged enough to survive the physical abuse experienced in downhillskiing. This system consists of an analog-to-digital converter that receives voltage differentials from the thermocouples through the wiring panel or the AM32 multiplexer board. The multiplexer board was capable of sampling 32 thermocouples and was used when more than five thermocouples were to be sampled. The wiring between the CR 10 and the multiplexer is shown in Figure 2.

The programs for controlling the $C R 10$ are given in Appendix A. Certain keystrokes enabled the skier to look at recorded and real-time temperatures. The real-time temperature readout was convenient for determining when the stationary ski was in thermal equilibrium. All of the data were stored in a solid-state storage module that was small enough to be put into the backpack too. The storage module was capable of storing 88,000 double accuracy data points, more than enough storagespace, even on a day when 30 or more runs were taken. Including the two $6-\mathrm{V}$ batteries, the backpack and its contents weighed about $10 \mathrm{~kg}$.

Type $T$ (copper-constantan) thermocouples were chosen because of their 5 - $\mu$ s response time and small size. Although the $0.5-\mathrm{mm}$-diameter thermocouple lead wires had advantages, they were too fragile for this application. During the course of the field tests, a number of thermocouples either gave erroneous values or quit completely. Some of these were replaced during the tests.

\section{Blitz ski}

This ski was selected because its homogeneous structure greatly simplified thermocouple em- 
placement and interpretation of the heat flow field. The Blitz ski was $1.1 \mathrm{~m}$ long, with an approximate apparent contact area of $0.05 \mathrm{~m}^{2}$. Five thermocouples were installed as illustrated in Appendix $B$, yielding both transverse and vertical temperature distributions in the ski. As shown in Appendix $B$, the thermocouple arrangement was changed after some use of the Blitz ski.

With only five thermocouples, the thermocouple lead wires could be connected directly to the CR 10 wiring panel located on top of the CR 10 data acquisition system. This increased the range of sampling frequencies, although for all runs with the Blitz ski, a 1-Hz sampling frequency was used.

\section{DH ski}

This ski is used in World Cup downhill races where ski glide is very important. The ski was 2.25 $\mathrm{m}$ long, with a contact length of approximately 2.1 $m$ and an apparent contact area of approximately $0.16 \mathrm{~m}^{2}$. The DH ski was constructed and instrumented by the Racing Department, RossignolS.A., in France. Appendix B (Fig. B2) shows where 32 thermocouples were placed in the DH ski at locations specified by us. The thermocouples were strategically located so that longitudinal, transverse and vertical temperature profiles could be recorded. This configuration yielded a three-dimensional matrix of temperatures in the ski. In addition, thermocouples were placed on one of the steel edges. To avoid erroneous readings, the thermocouples on the edges had to be insulated because of the electrical conductivity of steel. In the four-place designation of the thermocouples, the number in the first place indicates the longitudinal position in the ski and the letter in the second place means a vertical array (a), a basal array (b) or an isolated edge orbasal thermocouple (c). The last two places are for position in the vertical array (02 to 42 ), the position along the base (01 to 05), or an edge thermocouple (10) or an isolated basal thermocouple (02).

\section{Testing}

Various downhill ski areas were used as test sites. For each test, air and snow temperature, weather conditions and snow conditions were recorded at the beginning and end of each run. In particular, the air and snow temperatures were measured at the top and bottom of each run to account for the temperature variation with altitude. The snow temperature was measured by placing the ski in contact with the snow surface and reading the temperature of a basal thermocouple once it had stabilized. The air temperature was determined by placing the ski about $0.1 \mathrm{~m}$ above the snow surface and reading the steady-state temperature of the same basal thermocouple. Because of the fast response time of the thermocouples and their proximity to the base of the ski, we observed a steadystate condition within about 20 seconds when determining the snow and air temperatures. Once the test ski and thermocouple wires had been secured to the skier, the data acquisition system was programmed and the ski was allowed to rest flat on the snow until a steady-state temperature condition existed throughout the ski.

Each test consisted of a simple, but careful, ski run. Ideally, more control over the variables would have been possible; most of the test conditions were imposed on us by the prevailing conditions and the mechanics of skiing. Speed and load are highly variable because of changes in microtopography, temperature is affected by altitude and solar input, and snow type is affected by temperature, recentsnow falls and skier usage. We decided that, as long as the fluctuations in these parameters were recorded or reasonably consistent during each run, the results would be useful.

\section{Parameters affecting frictional heating}

Ambient snow temperature. Previous investigators have stated that the amount of frictional heat generated is dependent on the ambient snow temperature. Runs were made in which all of the parameters were consistent except the ambient snow temperature. There was some difficulty in determining this effect because, on any given day, the snow temperature did not vary more than a 4 or $5^{\circ} \mathrm{C}$ between the first and last runs. However, this small ambient temperature differential appeared to be sufficient to prove this effect, as is shown later. Since the upper limit of the basal temperature should be the melting temperature, tests were conducted at temperatures just below $0^{\circ} \mathrm{C}$ to see what temperature the base could reach.

Load. We tested the fluctuation of load at constant speed by cyclically weighting and unweighting the ski approximately every 20 seconds, while the skier was being dragged up a Poma lift. Once the Poma had attained constant speed, the skier applied approximately half of his weight $(N / 2)$ to the test ski and, 10 seconds later, applied all of his weight to the ski before returning to half of his weight 10 seconds after that. This loading pattern continued for the duration of the uphill run, at which point the ski was stopped so that it could attain a steady-state condition again. The speed of the slider in the snow track was about $2 \mathrm{~m} / \mathrm{s}$.

Tests of constant load during descent were done 
to have all three contributing factors to the rate of heat generation (load, speed and coefficient of friction) kept constant. Since neither the speed nor the coefficient of friction could be measured during the runs, very simple tests were conducted in which only the load varied between consecutive runs. Tests were conducted with loads of approximately $N / 2,3 N / 4$ and $N$ applied to the test ski.

Tests of turning at relatively low speeds were conducted with the skier continuously turning either left or right. The cyclicloading that occurred during turning should show how the rate of heat generation is affected by this loading pattern.

Tests utilizing an even weight distribution with the skier skiing in the parallel position in the tuck (or crouch) were done. This showed if the skier's weight is evenly distributed across the width of the ski.

Speed. Tests were conducted to determine the temperature increases that result from a difference in speed between downhill and uphill runs. The skis were kept parallel on a downhill run and the speed increased at an approximately constant acceleration. This test was repeated for a number of different loads ranging from $N / 2$ to $N$, and on runs of varying gradient.

Snow type. Tests were conducted on separate days when the snow type had dramatically changed because of changes in precipitation and temperature. Thus, tests were performed in snow conditions that varied from soft, fresh, wet snow to dry, hard-packed snow.

Thermal conductivity. One of the most important parameters affecting the temperature at the interface is the thermal conductivity of the slider. This effect was important to investigate because it is one of the few things in the design of any slider that can be directly controlled. It was investigated by measuring the temperatures in the vertical direction in both skis. Although identical ambient conditions never occurred during testing of both skis (i.e., the skis were never used on the same test day, but were taken out for testing on different days and therefore experienced different snow types and ambient temperatures), differences in the vertical profiles could illustrate the extent to which thermal conductivity affects the flow of heat from the frictional interface.

\section{Data processing}

At the end of a test session, the data were downloaded from the storage module to the hard disk of a personal computer. The data could then be converted into temperature versus time plots. Before graphing, we smoothed the data from both skis with a $0.5-\mathrm{Hz}$ filter to reduce the noise in the signal.

\section{Results and discussion}

Because of the highly dynamic conditions experienced in skiing, it was very difficult to isolate one parameter and determine its influence on the frictional heat generation. This problem was encountered throughout the experiments and can be attributed to the frequent variations in direction, load and speed that were experienced even on ski slopes that appeared smooth and of consistent gradient and snow type. In addition, it was difficult to quantify any of these parameters. Nevertheless, some useful information was produced, although the conclusions drawn from the study are mostly qualitative. The temperature versus time plots from the field study shown in Appendix Careonly examples of the data taken; many similar plots exist but are not shown because they are redundant.

\section{Effects of ambient temperature}

There is a definite trend, as shown in Figures C1 through $\mathrm{C} 4$, that suggests that the base of the test ski reaches a state of thermal equilibrium while still in motion. The temperature at which the base appears to have stabilized ranges from $-0.6^{\circ} \mathrm{C}$, when the ambient temperature was $-4.8^{\circ} \mathrm{C}$, to $0.2^{\circ} \mathrm{C}$, when the ambient temperature was $-0.25^{\circ} \mathrm{C}$. The fact that temperatures above the melting temperature of the snow were recorded can be attributed to the warm air, high solar input and a possible offset temperature in theinstrumentation. It is not known whether thermocouple 3 in Figure C1 had an offset temperature because it was destroyed before it could be calibrated. It had to be destroyed because it gave erroneous values during later tests. These plots indicate that although the speed of the ski was still increasing, the base reached a quasi-steady condition because of the generation of sufficient frictional heat to promote melting over the portion of the interface that was in contact.

This observation was apparent only with the Blitz ski, because we knew thelocation of the thermocouples in the Blitz ski to be on the base. In the $\mathrm{DH}$ ski, the thermocouples were located above the frictional interface, a small but unknown distance. This small distance was enough toseverely dampen their thermal response, which may also have been affected by the greater thermal conductivity of the DH ski. Nevertheless, if speeds greater than $18 \mathrm{~m} /$ $s$ and longer runs had been achieved with the DH ski at similar ambient temperatures (i.e., -5 to $0^{\circ} \mathrm{C}$ ), 


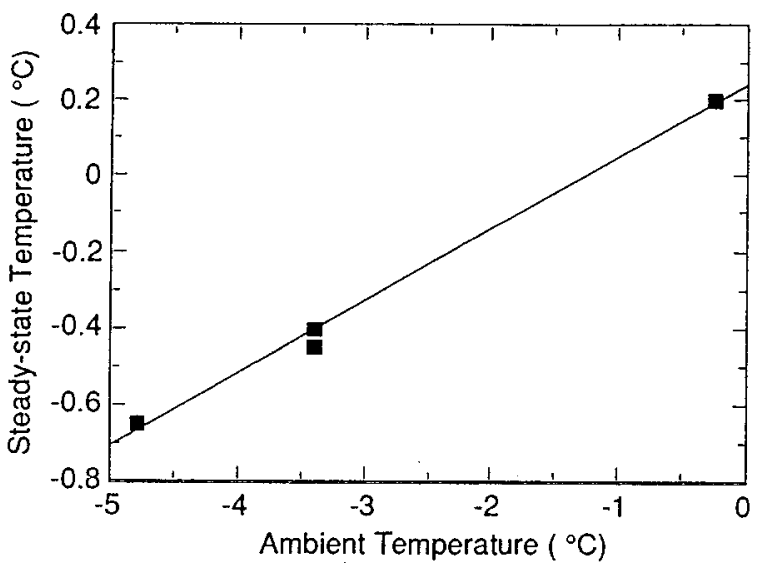

Figure 3. Steady-state vs ambient temperature for the Blitz ski.

similar plots showing steady temperatures might have beenobserved. Figure 3 shows a linear relationship between the ambient and steady-state temperatures as calculated from the data given in Figures $\mathrm{C} 1$ through $\mathrm{C} 4$.

The discovery that the base of a slider moving oversnow can attain a steady temperature supports the idea that meltwater at the frictional interface is responsible for the low friction of snow. Clearly, McConica's ideas about the thermal response of skis are incorrect. In addition, the interfacial temperature appears to be independent of the speed once the steady-state temperature has been reached. This idea is illustrated qualitatively in Figure 4.

Bowden and Hughes (1939) theorized, and it is often observed that, the coefficient of friction increases with decreasing ambient temperature. The reason for this is directly shown by the lower steady-state temperatures that we found at lower ambient temperatures. Coulomb or dry friction, which has a higher coefficient than the lubricated friction, is relatively more important at lower ambient temperatures. Since the rate of heat generation is proportional to the coefficient of friction, it appears that the greater rise in interfacial temperature at lower ambient temperatures is ascribable to more heat production resulting from a higher coefficient of friction. This effect can beseen in other runs that did not reach a steady-state temperature. Comparing Figures $\mathrm{C} 17$ and $\mathrm{C} 18$ shows that for an ambient temperature of $-9.8^{\circ} \mathrm{C}$, the temperature rise at the base of the ski was $5.3^{\circ} \mathrm{C}$, whereas for an ambient temperature of $-6.7^{\circ} \mathrm{C}$, the temperature rise at the base of the ski was only $3.3^{\circ} \mathrm{C}$. Apart from the change in ambient temperature, these two runs were nearly identical.

To quantify the heat flow as a function of the ambient temperature, data obtained from the base of the skis were fitted against the solution for the sudden onset of a constant heat flow. From Carslaw and Jaeger (1959, p. 75)

$$
T(t)=T_{0}+\frac{2 q_{\mathrm{s}}}{k_{\mathrm{s}}}\left(\frac{\kappa_{\mathrm{s}} t}{\pi}\right)^{1 / 2}
$$

where $T_{0}$ is the initial or ambient temperature. When the initial temperature rise was fitted against $t^{1 / 2}$ the resulting approximation always had a close fit. The values of the heat flow constant, or $2 q_{\mathrm{s}}\left(k_{\mathrm{s}} / \pi\right)^{1 / 2} / k_{\mathrm{s}}$, are shown versus ambient temperature in Figure 5. This shows that the heat flow at the base of the ski increases linearly as the ambient temperature decreases. At least over this narrow range of temperatures, the friction and heat

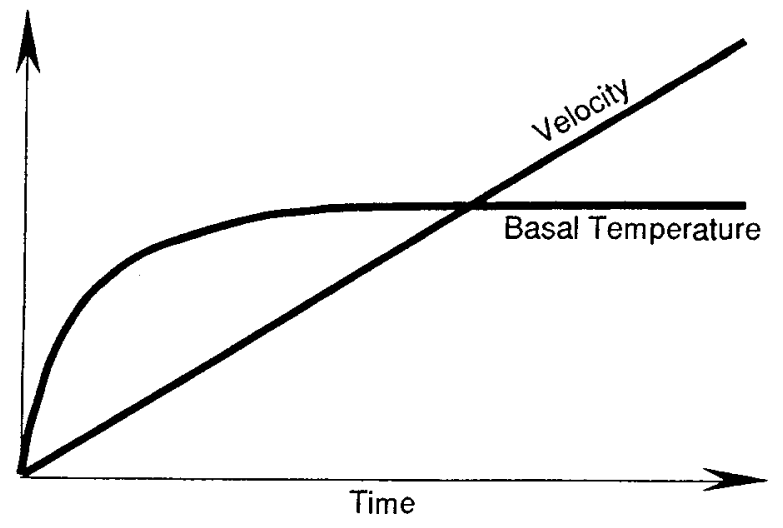

Figure 4. Independence of velocity and steady-state temperature for the Blitz ski.

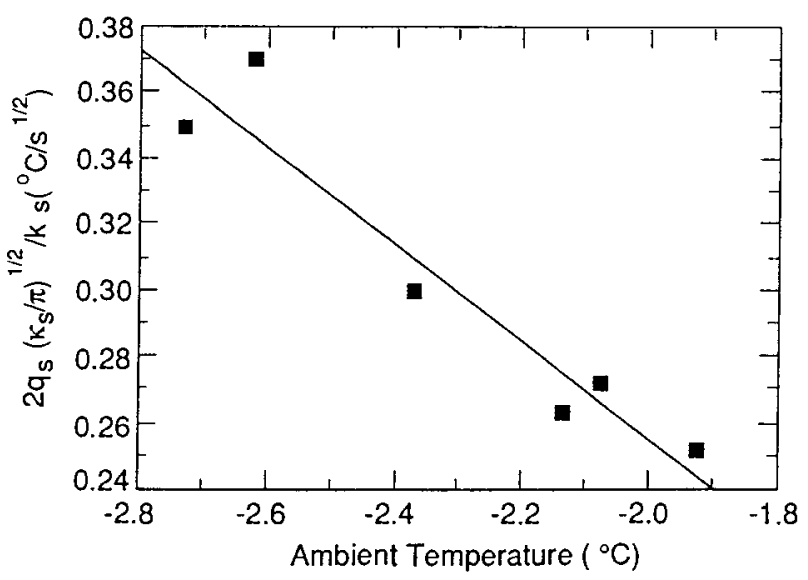

Figure 5. Heat flow constant vs ambient temperature for the Blitz ski. 
generation increase with decreasing ambient temperature.

\section{Effects of load}

Fluctuation of load at constant speed. Figure C10 illustrates the influence of load cycling on heat generation. The thermal response resulting from a change in load from $0.5 \mathrm{~N}$ to $N$ at a modest speed was surprisingly large. It is interesting to note that starting after about 50 seconds, a curve drawn through the peaks would approximate $t^{1 / 2}$. That is, although the load oscillates between the $N / 2$ and $N$, the resulting temperature response does not oscillate back and forth between the maximum temperature and the snow temperature because heat accumulates in the ski base.

This effect is also shown in Figure C19, in which the ski accelerates downhill, stops and accelerates downhill again in three cycles. The time between stopping and starting again was insufficient for the base to reach a state of thermal equilibrium. Therefore, when heat accumulates as the ski accelerates again, the ski attains a higher temperature than it did during the previous heating episode.

Different constant loads during descent. Using the responses from thermocouple 3 shown in Figures $\mathrm{C} 8$ and $\mathrm{C} 23$, as well as some of the data not included in Appendix $C$, we found an almost linear relationship between the load applied and the temperature rise. In each case the ambient temperature was approximately $-9.5^{\circ} \mathrm{C}$. This is in accordance with the eq 1, which suggests that the rate of heat generation is proportional to the applied load. This relationship is illustrated in Figure 6, in which the no-load data point is assumed to produce no temperature rise.

Turning. Figures $\mathrm{C} 5$ and $\mathrm{C} 6$ show the temperature rises associated with the turning of the ski.
Figure $\mathrm{C} 5$ shows the response of a basal thermocouple during a downhill run on a long, gentle slope. As is quite evident, the steady-state temperature is approached, but is never reached because of the weighting and unweighting during turning. Figure $\mathrm{C} 6$ shows the thermal response of two basal thermocouples that are located on either side of the base of the Blitz ski. The fast, smooth turns produced a significant thermal response from both sides of the ski. It is interesting to note two features in this figure. First, the alternate weighting and unweighting on each side of the ski during turns produced a $180^{\circ}$ phase lag between the two basal thermocouples. Second, the average thermal response of thermocouple 1 is greater than that of 5 . This can be attributed to the inside location of thermocouple 1 and the outside location of thermocouple 5. In downhill skiing, more weight is applied to the downhill ski during a turn. In the case of the Blitz ski, which was placed on the right foot for all tests, the left inside edge would experience more loading when negotiating a left-hand turn than the outside edge would experience during the same turn. Therefore, thermocouple 1 was more heavily weighted than thermocouple 5 and shows a greater thermal response.

Loading with skis parallel. It was surprising to discover the large temperature rise across the ski when the load appeared to be evenly distributed during a parallel schuss. Figures C11 and C12 show this effect, which is caused by the amount of edging that a skier applies when in the parallel tuck position. This nonuniform distribution of weight can be attributed to the technique required to maintain stability when skiing in that position. The amount of edging required appears to be a function of the hardness of the snow as illustrated in Figure 7. This graph indicates that the tempera-

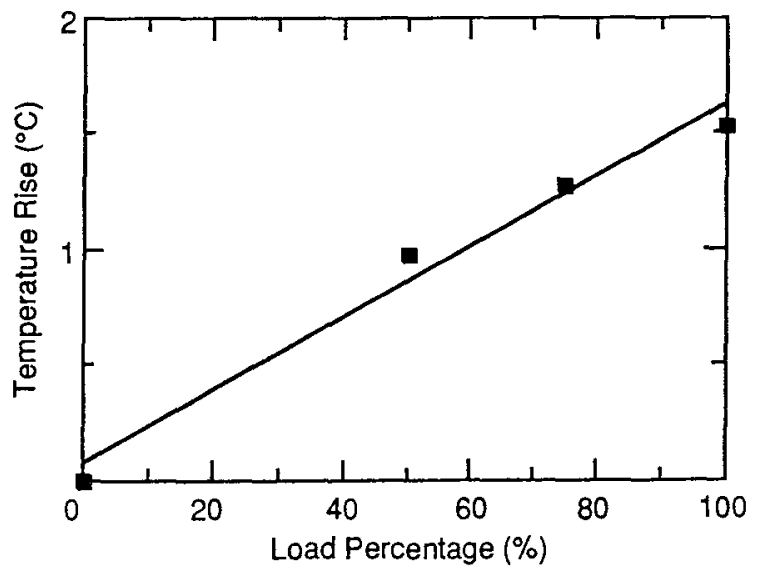

Figure 6. Temperature rise vs load for the Blitz ski.

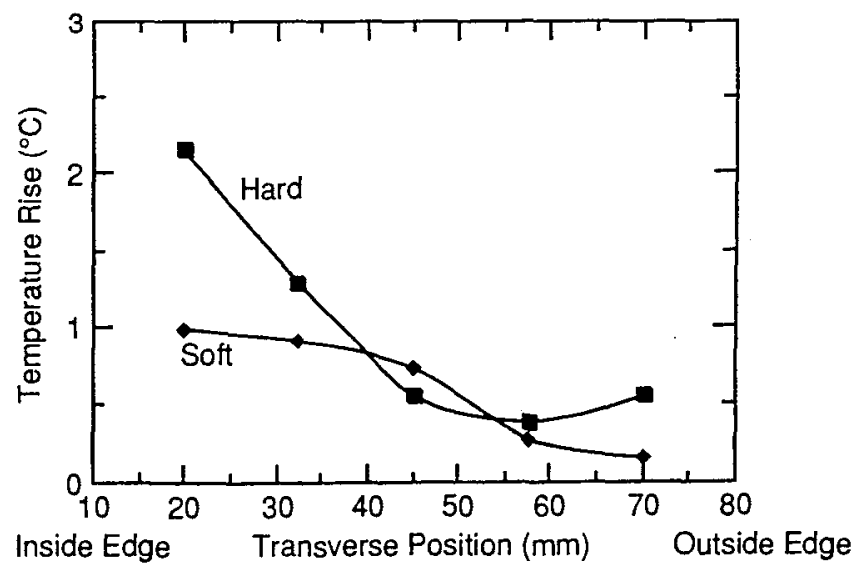

Figure 7. Temperature rise vs transverse position for two snow types. 
ture is more uniformly distributed across the ski when the snow has a low hardness. This is apparently attributable to the more even distribution of load when the soft snow conforms to the shape of the ski. A similar effect of soft snow will be shown later when we discuss the longitudinal profiles.

Effects of speed. This parameter was by far the hardest to control or record, largely because of the variations in terrain, lack of an appropriate measuring device and supporting personnel. However, the thermal response as a function of speed is described in a qualitative sense in Figure $\mathrm{C} 22$. The large temperature rise of approximately $4^{\circ} \mathrm{C}$ at the beginning of this run is from a maximum speed of approximately $6 \mathrm{~m} / \mathrm{s}$. At 60 seconds, a smaller temperature rise of approximately $2^{\circ} \mathrm{C}$ is due to the reduced speed on the Poma lift.

Effects of snow type. To further determine the effects of snow hardness on the heat production rate, the longitudinal profile was analyzed. This yielded some interesting results, as shown in Figures $\mathrm{C} 13$ through $\mathrm{C} 16$. Figures $\mathrm{C} 13$ and $\mathrm{C} 14$ depict the longitudinal thermal response at the base of the ski on hard-packed snow. Close inspection of the thermocouple response associated with each curve shows that in icy conditions, most of the heat generation occurs in the vicinity of the center of the ski (i.e., directly under the skier). In the case of soft snow (Fig. C15 and C16), the weight is distributed far more evenly, probably because the soft snow conformed to theshape of the ski. The temperature rise as a function of longitudinal position for hard and soft snow is illustrated in Figure 8.

The apparent heat flow distribution in the longitudinal direction caused us to pose some questions. Is the temperature increase at the rear of the

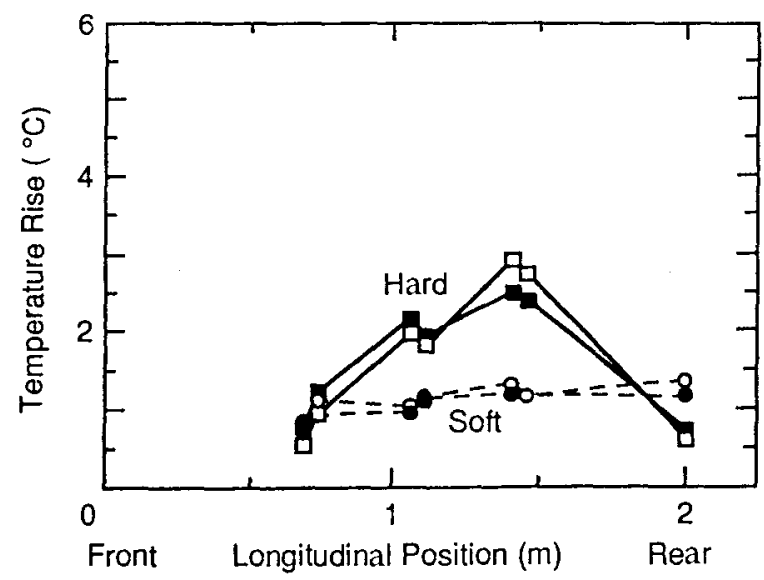

Figure 8. Temperature rise us longitudinal position for different snow types. ski on soft snow at tributable to an accumulation of heat along the ski or is it ascribable to the load distribution? An experiment was conducted in which the static load distribution for the DH ski in the longitudinaldirection was measured. To determine the pressure distribution along the length of the ski, six plastic disks were machined with crosssectional areas of $16.4 \mathrm{~mm}^{2}$. This value was chosen so that the pressure applied on the disks would be large enough to be measurable on the Fuji pressure film that was available to us. The disks were equally spaced along the base of the DHski and the pressure film was placed between the disks and a hard, flat surface. The weight of the skier was then applied for a couple of minutes until the film responded. This procedure was repeated to give the average pressure of the two tests at each node as illustrated in Figure 9.

This graph indicates that there is more pressure at the rear than the front of the ski, so more heat would be generated at this location. In addition, this graph indicates that the largest load is applied directly under the skier, which explains why, on hard snow at least, a large thermal response was measured under the skier. It appears that the largest thermal response occurs at the rear of the ski in soft snow conditions, and this might be attributed to the accumulation of heat along the length of the ski as well as the increased pressure at this location under soft snow conditions.

Effects of thermal conductivity. Figure $\mathrm{C} 7$ shows the response at two positions in the Blitzski. Thermocouple 1 was on the base and responded as we have seen before. Thermocouple 2 was $3.8 \mathrm{~mm}$ above the base and responded much less and much later. The difference between the two can be

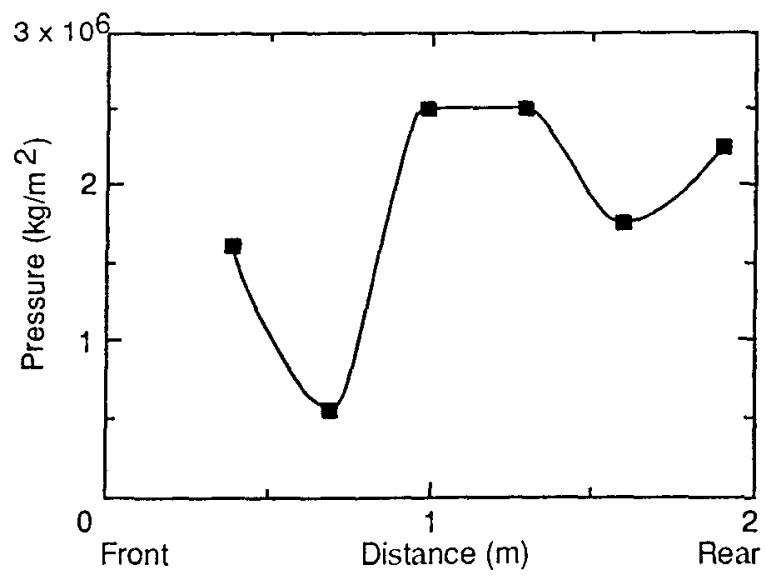

Figure 9. Pressure vs distance from front of $\mathrm{DH}$ ski. 


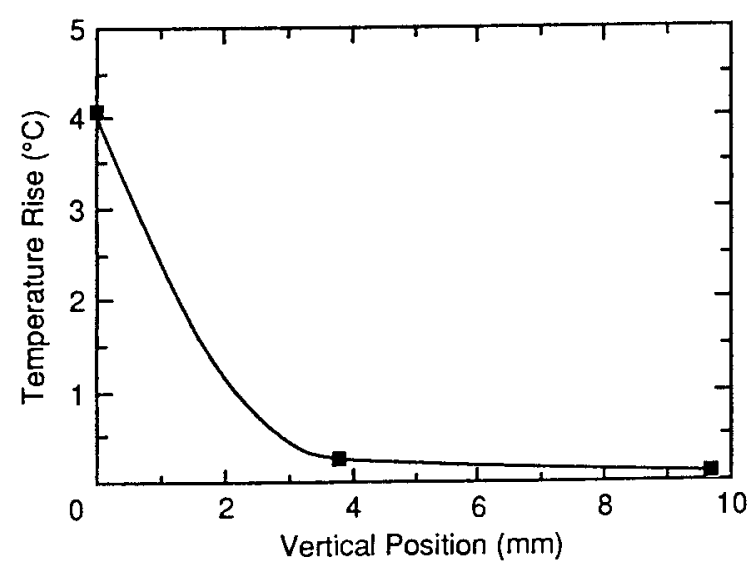

Figure 10. Temperature rise vs vertical position in the Blitz ski at $-9.5^{\circ} \mathrm{C}$.

attributed in part to the poorly conducting plastic of the Blitz ski. In Figure $\mathrm{C} 8$ the responses of three thermocouples on the base and two above the base are shown. Thermocouple 4 , which was $9.7 \mathrm{~mm}$ above the base, hardly responded to the heat generation. It is interesting to note that the temperature at this location falls off at the initiation of motion. This effect can be attributed to convective air cooling, implying that the top of the ski was not at the ambient temperature, even though it appeared to be in thermal equilibrium. This convective effect could have occurred because the top of the ski received heat either from the sun or from the skier's boot. Figure 10 shows the dampening of the thermal response with height of thermocouples 2,4 and 5 of Figure C8.

Figure $\mathrm{C} 9$ shows the vertical response of the $\mathrm{DH}$ ski with thermocouples located at approximately the same vertical positions as in the Blitz ski. Note that the relative thermal response of the thermocouples away from the base ( $2 \mathrm{a} 22$ and $2 \mathrm{a} 32$ ) are much greater than the response in the Blitz ski. This is because thermocouple $2 \mathrm{a} 22$ is situated on top of the aluminum plate, as shown in Appendix B. The high thermal conductivity of this plate increases the thermal response so much that a thermocouple off of the base in the DH ski (2a22) has about the same fractional response as a thermocouple on the base (5) of the Blitz ski, as shown in Figure 11.

A comparison of Figures $\mathrm{C} 20$ and $\mathrm{C} 11$ shows the variation of response time with thermal conductivity during the same run. (The ambient temperature differs in these figures because of a calibration error.) In Figure C20, the two thermocouples on the steel edge ( $3 \mathrm{c} 10$ and $4 \mathrm{c} 10$ ) began to respond almost immediately, whereas the base

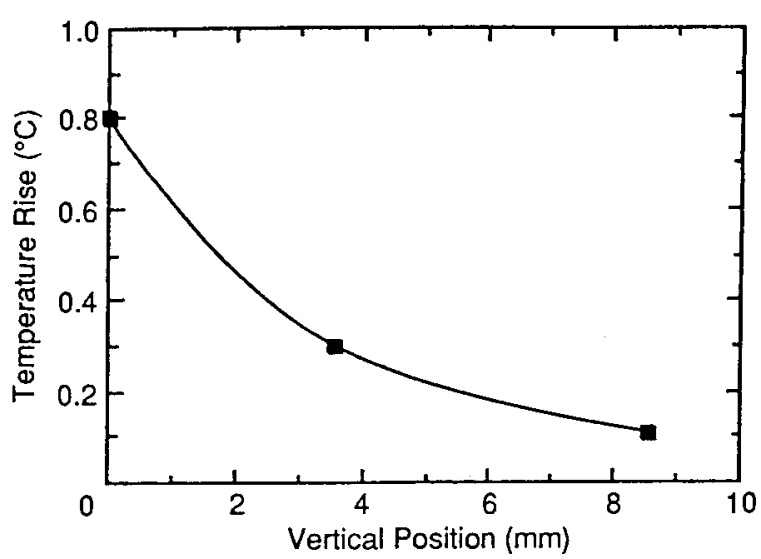

Figure 11. Temperature rise vs vertical position in the DH ski at $-1.8^{\circ} \mathrm{C}$.

thermocouple ( $5 \mathrm{c} 02$ ) responded after 4 or 5 seconds. In Figure C11, which shows only base thermocouples, the response begins more quickly but only $2 \mathrm{~b} 01$ responded as much as $3 \mathrm{c} 10$. Response is delayed not only because of the effect of thermal conductivity but also because the base thermocouples in the DH ski are a small but finite distance away from the base.

\section{Additional obseroations}

Variation of temperature with altitude. Figure C17 shows the change in temperature that occurs with altitude. In this case, the snow temperature is approximately $1.3^{\circ} \mathrm{C}$ lower at the top of the run than it is at the bottom. This observation indicates that a small component of the temperature rise that takes place during a descent may be caused by this altitude effect.

Real location of basal thermocouples in Blitzski. Figure $\mathrm{C} 8$ shows a very large difference in thermal response among the three basal thermocouples ( 1 on the left side, 3 in the middle and 5 on the right side of the Blitz ski.) This might be attributable to the uneven load distribution in the transverse direction during parallel skiing as described earlier. This cannot be the case, however, because this explanation would require that thermocouple 1 have the strongest response and thermocouple 5 have the weakest. The reason for the different thermal responses is that these thermocouples are not located at precisely the same heights above the base of the ski, an effect that is especially important in the non-conductive plastic. Figure $\mathrm{C} 21$ shows the same response but with the time axis expanded. Inspection of the response time suggests that thermocouple 3 is closest to the base, followed by 5 and 1. To correct this problem, new thermocouples 
were placed in the base of the Blitz ski and a typical response of these is shown in Figure C22.

\section{Smoothing of data}

Figure $\mathrm{C} 24$ shows the response of a basal thermocouple as actually recorded. The fluctuations in thermal response during the run may be caused by electronicnoise as well as physical effects, including frequent variations in load due to the topography of the ski slope. These undesirable effects were reduced using a smoothing routine with a cut-off frequency of $0.5 \mathrm{~Hz}$, which allowed earlier comparisons between files. A smoothed version of Figure C24 is shown in Figure C23 for comparison.

\section{FINITE ELEMENT MODEL}

\section{Computational procedure}

Purpose of computer simulation of frictional heat flow in skis

As a second phase to this project, we used a computer model to simulate the flow of frictional heat into a downhill racing ski to try to quantify the significance of thermal conductivity and material geometry on the heat removal from the interface. The computer model made use of the finite element method to determine the temperature distribution in a rectangle that represented the cross section of the ski. The temperature fields generated by this model were compared with the temperatures recorded in the field to see if the model could be a useful tool to predict the heat flow characteristics of various ski structures and ambient conditions. This would eliminate the expensive and tedious task of building and testing sliders of all types to determine their thermal response.

\section{Finite element software and parameters}

The THERMAP (Thermal Analysis Program) software available on the NORTHSTAR computer network at Dartmouth College (Glovsky 1982) was chosen for this computer simulation because of its flexibility in handling a wide variety of thermal phenomena, including conduction, convection, internal heat generation, surface heat flux and phase change. In addition, the program is capable of calculating the transient and steady-state solutions of the temperature distribution, both of which are of great interest in frictional heating. Many of the input parameters were based on observations and measurements from the field study.

To use the finite element method, a mesh had to be created, which involved breaking up the cross section of the DH ski into a number of small elements. Making use of symmetry, we modeled only one half of the width of the ski with a no-heatflow boundary condition imposed on the right side of the mesh at the center-line of the ski. To determine the element dimensions and shapes, a section was cut from an old DH skiand the material dimensions and configuration were measured. Furthermore, the size of the individual elements was based on theexpected heat flow in themedium. The elements were small in locations where the temperature gradients were large. In the case of a ski sliding over snow, the elements were smallest at the base of the ski, where the heat is generated. We incorporated 185 triangular elements into the mesh. A larger number of elements could have been used, but for this application, the additional resolution in the mesh would have required extremely long computer runs. The 185 elements werecreated from the 114 nodes that were specified; the node coordinates are the locations at which the resulting temperatures are calculated. A schematic of the mesh chosen for the frictional heat flow in the DH ski is illustrated in Figure 12.

For the first 17 seconds of each run, a heat flux boundary condition resulting from frictional heating at the base of the ski was specified. The heat generation was determined using eq 1 with half of the skier's weight assigned to each ski. The coefficient of friction was taken as 0.06 , the speed was estimated as $18 \mathrm{~m} / \mathrm{s}$, and the area was calculated as $0.16 \mathrm{~m}^{2}$ by measuring the length and width of the apparent contact area of the DH ski. This speed is close to the upper limit of that encountered with the DHski but is less than racing speeds. Actual contact only occurs over a small fraction $(\sim 4 \%)$ of thebase of the ski. Using this area would increase the heat flux by a factor of 25 but would be applied to only $4 \%$ of the base of the mesh in the model. Assuming that thesnow crystals come in contact with all of the ski at some time and that these contacts vary randomly and frequently, we deemed it reasonable to apply the heat flux across the entire base of the ski with a value corresponding to $100 \%$ contact area.

All of this heat flows into either the ski or the snow since melting has not yet begun. Using this balance, eq 8 for both the snow and the ski, and noting that the surface of the snow and the ski are at the same temperature, we can easily show that the heat flow ratio $(R)$ is given by

$$
R=\frac{k_{\mathrm{s}}}{k_{\mathrm{i}}}\left(\frac{\kappa_{\mathrm{i}}}{\kappa_{\mathrm{s}}}\right)^{1 / 2} \text {. }
$$




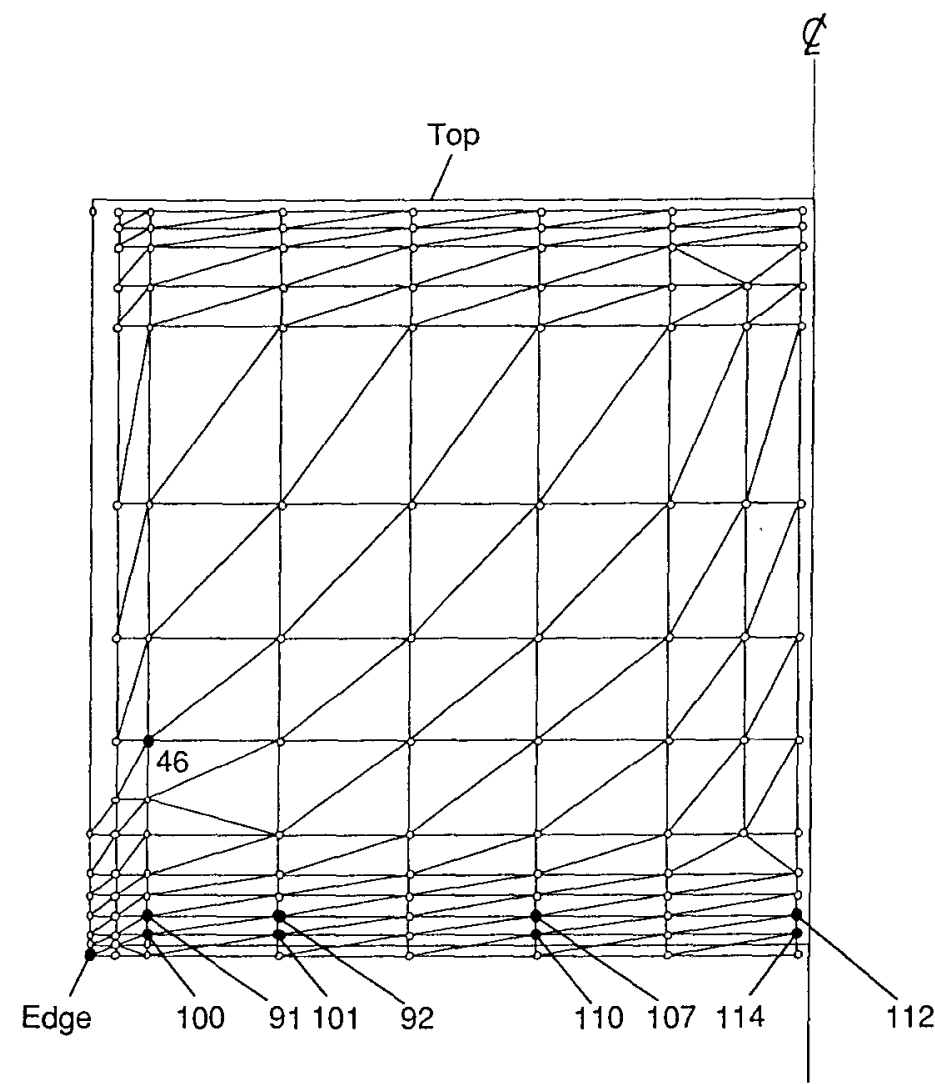

Figure 12. Finite element mesh with node numbers. Dimensions are in millimeters. The righthand edge is the centerline of the ski and the left-hand edge is the side of the ski.
Using the values $k=0.377 \mathrm{~W} / \mathrm{m} \mathrm{K}, k_{\mathrm{i}}=0.552 \mathrm{~W} /$ $\mathrm{m} \mathrm{K}, \mathrm{K}_{\mathrm{s}}=10^{-7} \mathrm{~m}^{2} \mathrm{~s}$, and $\kappa_{\mathrm{i}}=1.3 \mathrm{~m}^{2} / \mathrm{s}$ yielded a value of 0.438 for $R$. Therefore, the rate of heat flux into the ski was taken as

$$
q_{\mathrm{s}}=\frac{R}{1+R} \mu \nu N
$$

This was the value used in all cases simulating frictional heating.

As an alternative, a fixed temperature condition could be imposed on any number of nodes within the mesh. From observations made in the field study, we determined that once the skibase reached a steady temperature, this steady-state condition was maintained for the duration of the run; its value in most runs was above $-1^{\circ} \mathrm{C}$. To simulate this temperature condition in the model, the program was stopped once the base had attained temperatures within this range. A fixed temperature was then imposed on the basal nodal points, and the simulation continued.

In the case where a rise and subsequent fall in the vertical temperature profile was determined, it was possible to simulate the deceleration of the ski using appropriate values for basal temperature.
This was achieved by decrementing the temperature of the basal nodesin a way that approximately replicated the temperature decreases observed in the field data during deceleration of the ski. Once again, we did this by stopping the program to adjust the fixed temperatures of the basal nodes to simulate the cooling effect observed in the field.

Internal heat generation from flexing could have been included but, from the data gathered in the field, there is no indication that heat was being generated at any location other than the base of the ski. The effects of convection ascribable to motion occur along those boundaries that were exposed to the air, the left and top side of the mesh. The convection coefficient was determined using the equation (Kays 1960)

$$
H=7.25 v^{4 / 5}
$$

where the speed was taken as $18 \mathrm{~m} / \mathrm{s}$ ( $H$ being given in $\mathrm{W} / \mathrm{m}^{2}{ }^{\circ} \mathrm{C}$ ). This value was used for all simulations. Values of the properties of the materials used in the mesh, including the thermal conductivity and diffusivity, are given in Table 1.

Case studies of heat flow into the DH ski

We used four case studies to investigate the 
Table 1. Thermal properties of materials in DH ski.

\begin{tabular}{lcrr}
$\quad$ Material & $\begin{array}{c}\text { Thermal } \\
\text { conductioity } \\
(\mathrm{W} / \mathrm{m} \mathrm{K})\end{array}$ & $\begin{array}{c}\text { Thermal } \\
\text { diffusivity } \\
\left(\mathrm{m}^{2} / \mathrm{s}\right)\end{array}$ & $\begin{array}{c}\text { Specific } \\
\text { heat } \\
(/ / \mathrm{kg} \mathrm{K})\end{array}$ \\
\hline Polyethylene & 0.4 & $2 \times 10^{-7}$ & 2310 \\
Steel & 50 & $1.5 \times 10^{-5}$ & 470 \\
Snow at $0^{\circ} \mathrm{C}$ & 0.55 & $1 \times 10^{-7}$ & 4200 \\
Wood & 0.2 & $1 \times 10^{-7}$ & 2390 \\
Aluminum & 190 & $8 \times 10^{-5}$ & 900 \\
Fiberglas & 0.2 & $1 \times 10^{-7}$ & 1680 \\
Plastic & 0.2 & $9 \times 10^{-8}$ & 1220 \\
Air at $0^{\circ} \mathrm{C}$ & 0.02 & $2 \times 10^{-5}$ & 960 \\
\hline
\end{tabular}

effect of thermal conductivity on the retention of heat at the base of a slider. For each case, both the transient and steady-state solutions for the temperature distributions were determined. These cases are as follows.

Case 1. The temperature distribution was calculated for the actual RossignolDH ski, incorporating both the aluminum plate near the base and the steel edge. This case gave the heat flow characteristics of this popular downhill racing ski. This configuration is shown in Appendix B.

Case 2. The temperature distribution was calculated for the DH ski with the steel edge replaced by a ceramic edge. The removal of the highly conductive steel edges might allow greater melting and give lower friction at low temperatures. This could be achieved by substituting a high strength, poorly conducting material, such as sintered alumina, for the steel.

Case 3. The temperature distribution was calculated with the steel edge replaced with the ceramic edge and the lower aluminum plate replaced with a layer of polymer. The vibration-dampening aluminum layer used in racing skis was thought to be a significant heat flow conduit because of its very high thermal conductivity, geometry and location in the ski. We hoped that the replacement of this aluminum layer with a material of much lower thermal conductivity but comparable stiffness, such as polyoxymethylene, would reduce the heat flow along this layer, resulting in greater retention of heat at the base.

Case 4. The temperature distribution was calculated for a ski with the aluminum layer replaced with the polyoxymethylene layer but with the steel edge reinserted. This material configuration was analyzed to determine if the two metal components interacted to enhance the heat removal.

A list of the thermal properties of materials in the actual and altered DH ski is given in Table 1.
Limitationsand problemsencountered with THERMAP

In the transient solutions, there was a small amount of heat flow across the centerline of the ski, which was designated as a no-heat-flow boundary. This could have been caused by the selection of mesh size and element configuration. However, the effects of this problem were small and we considered them insignificant because our interest was primarily in the heat flow along the base and out the sides of the ski.

In trying to simulate the temperature response at the base of the ski as observed in the field study, we used a heat-flux boundary condition to start the computation, as described above. Its use was limited, however, because the temperature at the base was limited to the observed steady-state temperature. Thus, the boundary condition at the base was adjusted according to the calculated temperatures. This required frequent pauses in the execution of THERMAP to a djust the heat flux or impose fixed temperatures on specific nodal points. This procedure is somewhat arbitrary but is not unrealistic since the friction and the heat production vary with time after the start of motion in a real ski. It would have been convenient to set these parameters in an additional file that would have been capable of adjusting the heat flux values and the convection coefficients at the specified times and locations, but the actual heat flux could not be determined from data collected in the field. Apart from this limitation, the THERMAP software package was an appropriate tool in determining the temperature responseresulting from frictional heating.

\section{Results and discussion}

The finite element heat flow analysis was done to examine the significance of thermal characteristics to the heat flow propagation in a slider. The results presented and discussed in this section yield some interesting insights into the heat flow, and thus we hope that this model can be used to predict the thermal and frictional behavior of sliders.

As noted above, for about the first 17 seconds the heat flow parameters assigned were based on continuous heat generation calculated from eq 10 and the area of the ski. This initial period of constant heat generation does not take into account the effects of weight or speed change that occurred in the field study because of the difficulty of adjusting the prescribed temperatures at nearly every time increment. When the base reached a temperature that was comparable to the steady-state temperature measured in the field, that temperature was 
fixed to the basal nodes and this condition was maintained until the entire ski was in a state of thermal equilibrium. Since the replication of a common ski run was desired, the basal temperatures were also modified to simulate the cooling experienced at the base as the ski decelerated and stopped. This simulation allowed a qualitative comparison between the vertical thermocouple response in the model and the test ski.

\section{Transient thermal response of the} actual DH ski (case 1)

Figures D1 through D10 illustrate the transient heat propagation through the ski until a steadystate condition has been achieved. These plots of isotherms show how the temperature distribution varies with time, illustrating the long time required before the entire ski is in a complete state of thermal equilibrium. To show this, the temperature of node 46 (see Fig. 12) in case 1 was plotted as a function of time and is shown in Figure 13. Thissuggests that the time required for the entire ski to achieve complete steady-state far exceeds the time of a standard downhill competition run. Except at the base of the ski, the idea of steady state may not be applicable to skis because of the frequent changes in speed, direction and load experienced under nearly all skiing conditions.

\section{Vertical thermal response}

We did this computer run to determine the thermal characteristics of nodes in the ski that ap-

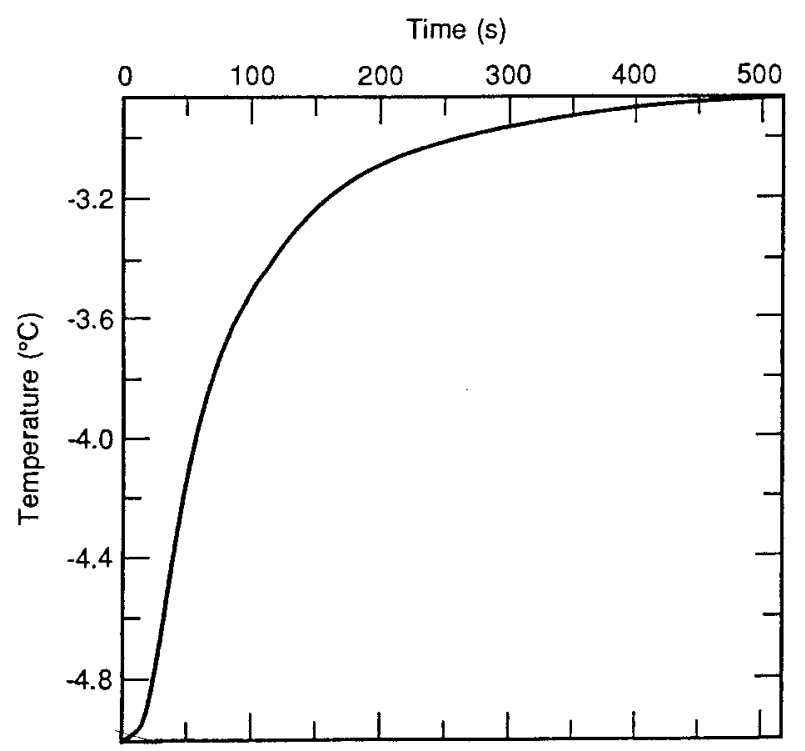

Figure 13. Temperature rise at node 46 us time for case 1. proximately represent the measured vertical temperature profile in the $\mathrm{DH}$ ski. It should be noted that the computer simulation represents an ideal downhill run consisting of no intermittent heating, uniform heating across the base of the ski, and a run time representing the time of a normal downhill competition run. Because of these assumed conditions, only a qualitative comparison can be made between model and field results. The response of the computer simulation, shown in Figure 14, is typical of the amplitude-dampened, phase-lagged behavior observed in the real ski and shown in Figure C9.

Thermocouple na 02 reached a plateau at a temperature of approximately $-1^{\circ} \mathrm{C}$, thus simulating what was observed in the field data. The thermocouples furthest away from the base of the ski (na32 and na42) cool off before experiencing the frictional heat propagating up from the base. In the real ski, this was attributed to the effects of convection. However, in the model this can only be attributed to computational inaccuracy.

\section{Heat flux at the base}

The heat flux perpendicular to the base was computed at four places along the base (see Fig. 15) because that is where the critical heat removal takes place. It is clear from these plots that the local heat flux is strongly affected by material composition and is very dependent on the location along the base. As expected, heat flux increases with increasing thermal conductivity, but the effect is not

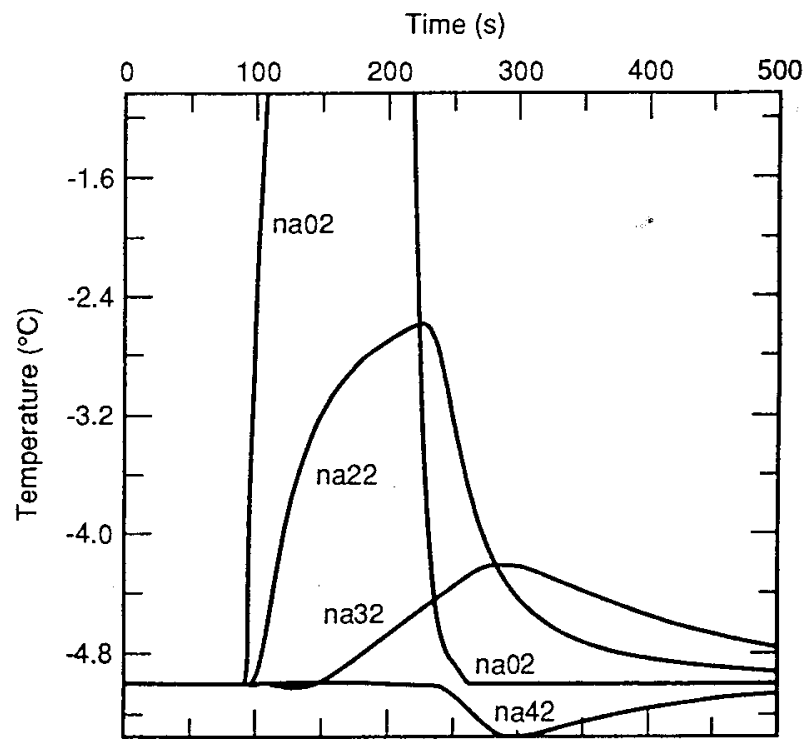

Figure 14. Computed vertical temperature profile for nodes $110,76,58,40$ (equivalent to thermocouples na02, na22, na32, and na42 respectively). 


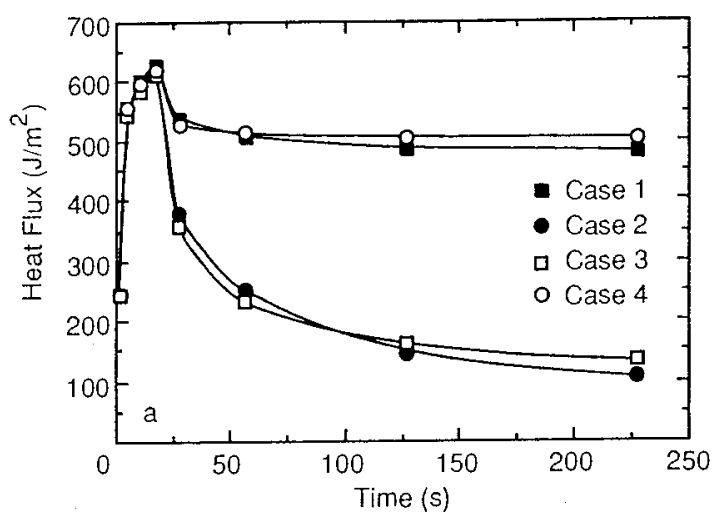

a. Between nodes 100 and 91 .

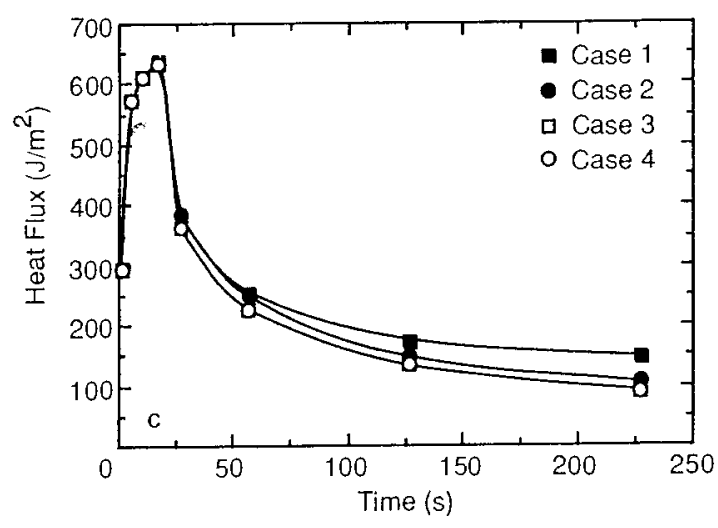

c. Between nodes 110 and 107.

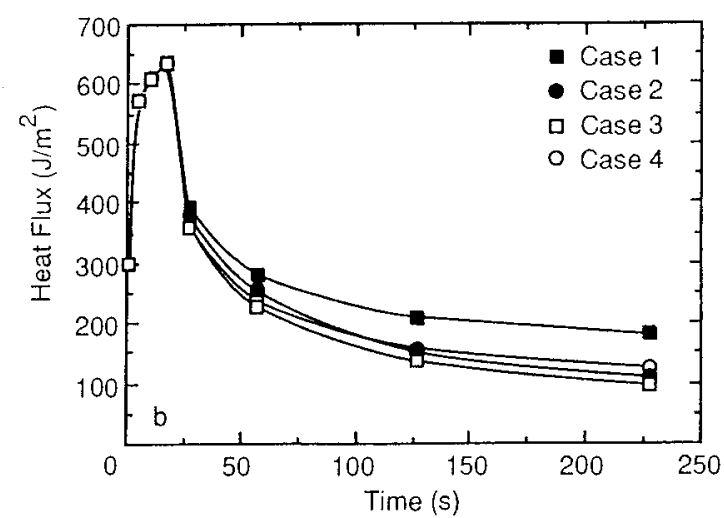

b. Between nodes 101 and 92 .

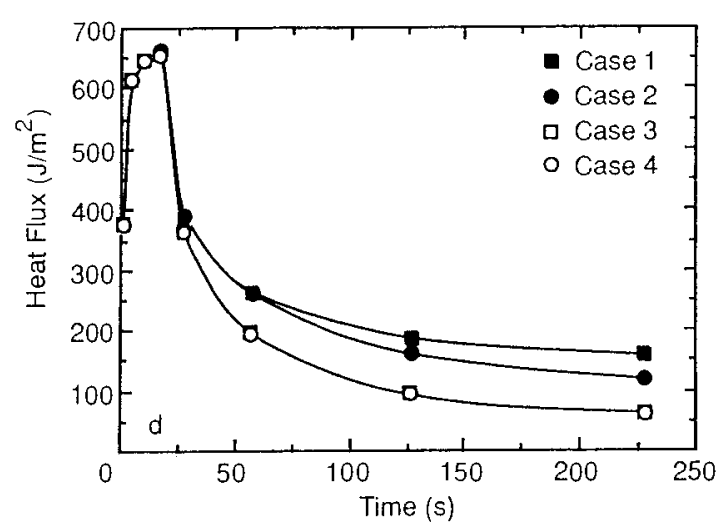

d. Between nodes 114 and 112 .

Figure 15. Heat flux versus time.

uniform throughout the complexgeometry of this ski. Case 1 incorporated an aluminum plate with a steel edge; case 2 incorporated an aluminum plate with a ceramic edge; case 3 incorporated a polymer plate with a ceramic edge; and case 4 incorporated a polymer plate with a steel edge. The locations of the nodes in this heat flux analysis are shown in Figure 12.

Figure 15a shows the heat flux as a function of time between basal nodes 100 and 91, which are located approximately $3 \mathrm{~mm}$ from the edge of the ski. The heat flows in cases 1 and 4 with the steel edge are about four times greater than in cases 2 and 3 with the ceramic edge, at least at a time of 227 seconds. This suggests that the steel edge dominates the heat flow pattern this close to the edge. The retention of heat near the side of the ski base is increased significantly when a material of low thermal conductivity is used in place of steel.

The effects of the steel edge and the aluminum plate on the heat flux at the base of the ski are about equal at a distance of $10 \mathrm{~mm}$ from the edge. In the case of basal nodes 101 and 92 (Fig. 15b), both the steel edge and the aluminum plate are needed to make a significant difference. Clearly, the heat flux becomes more dependent on the aluminum plate than on the steel edge as the distance away from the edge increases. The heat flow between nodes 110 and 107 , located $25 \mathrm{~mm}$ away from the edge, is shown in Figure $15 \mathrm{c}$. The heat fluxes at 227 seconds for cases 3 and 4 are very similar to but slightly less than that of case 2 (aluminum plate, ceramic edge). The aluminum plate really dominates other effects at $37 \mathrm{~mm}$ away from the edge as shown in Figure $15 \mathrm{~d}$ for nodes 112 and 114 . Cases 1 and 2 with the aluminum plate provide the greatest amount of heat flow and would reduce the amount of heat at the base of the ski in its midsection by $50 \%$ or more.

\section{Steady-state temperature distribution}

Figure 16 illustrates the steady-state temperature distribution of cases 1 through 4. Cases 1 and 2 (Fig. 16a and b) with the aluminum plate show that a large amount of heat is conducted along the 


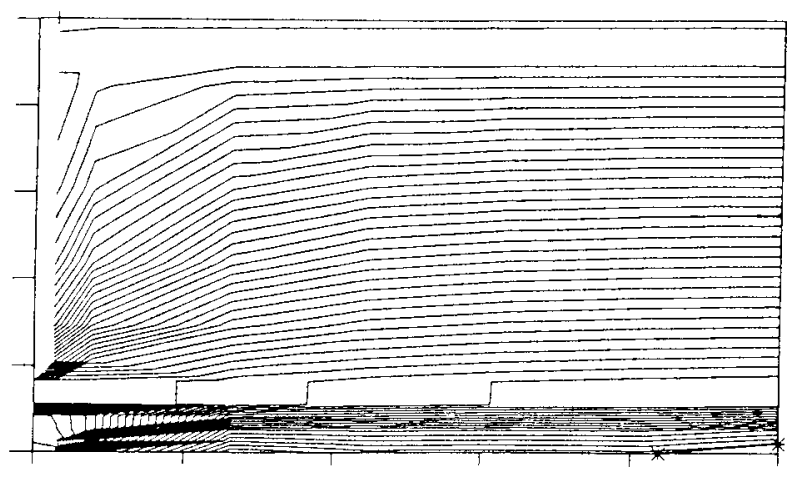

a. Case 1 .

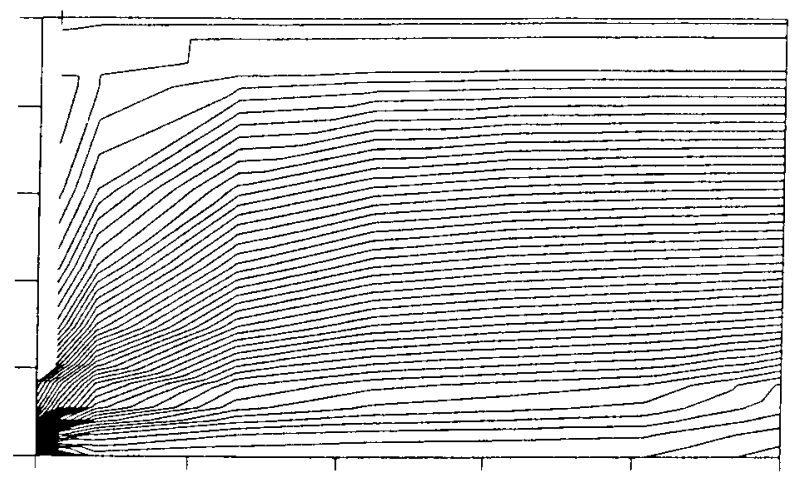

c. Case 3 .

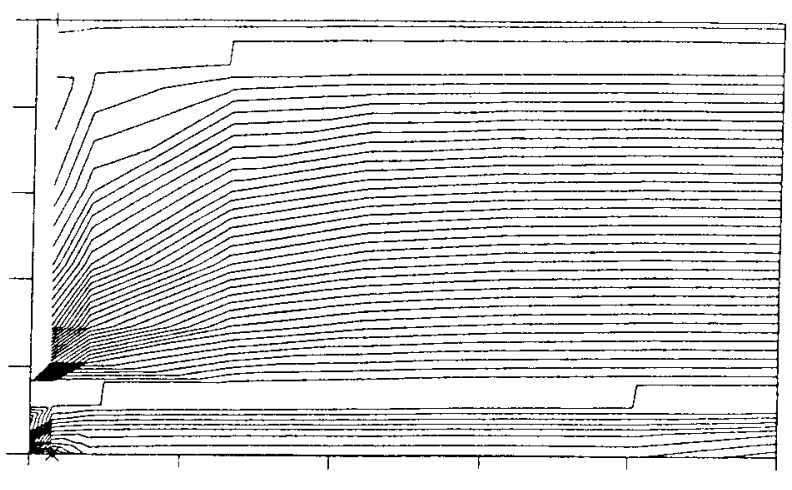

b. Case 2 .

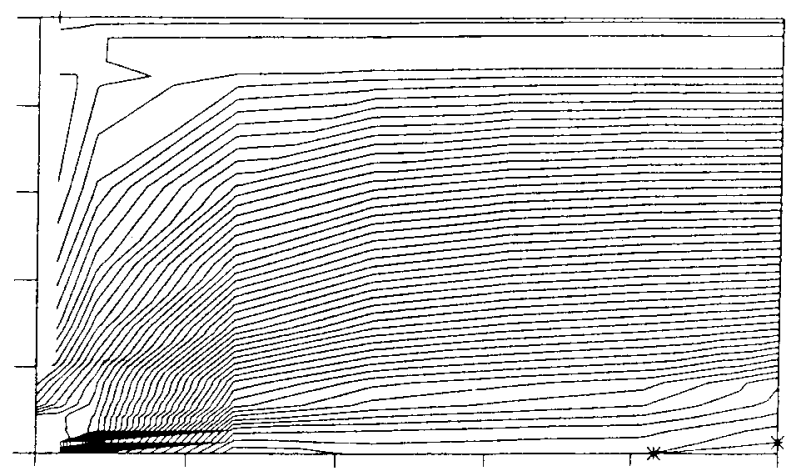

d. Case 4 .

Figure 16. Steady-state temperature distribution.

aluminum plate to the outside wall of the ski, whereas in cases 3 and 4 (Fig. 16c and d) the horizontal component of heat flow in the polymer plate is significantly reduced. This suggests that, when the entire ski is in an overall state of thermal equilibrium, a considerable amount of heat is lost through the side of the actual ski. Figures $16 \mathrm{c}$ and $\mathrm{d}$ show that the most of the heat flows vertically up into the ski and that the presence of the polymer reduces the total heat flow, although there is still a significant corner effect from the steel edge in Figure 16d.

In an effort to quantify this, we measured the perpendicular distances between adjacent isotherms for each case to determine the magnitude of the heat flow in the plate and the surrounding material. Results indicate that for case 1, the heat flux along the aluminum plate is approximately 40 times as great as the heat flow into the wood just above the aluminum plate. In case 2, the replacement of the steel with ceramic reduces this ratio to approximately 15 . This reduction occurs in spite of the downward heat flow in the vicinity of the steel edge. In cases 3 and 4 this ratio is reduced to approximately 1 , thus showing a greatly reduced heat loss out of the sides of the ski. This analysis clearly suggests that thereplacement of conductive materials would reduce the heat flow away from the base and could greatly affect the ski's friction at lower temperatures.

The heat flow in the wood core is not greatly affected by the change in material composition, perhaps by no more $20 \%$. In case 1 , so much heat is conducted along the aluminum plate that heat flows downward through the steel edge. However, this may be a feature attributable to the boundary conditions that were imposed on the model.

\section{A qualitative comparison between the field study and the finite element model}

A qualitative comparison was made between the results of the field study and the results of the model partly to test the validity of the model.

Transicut response

For the first 17 seconds of a model rum, a constant 
heat flux was imposed on the ski base. In the field study, it took a certain amount of time to attain this maximum speed, which would suggest that the amount of heat generated at the base increased from zero to its maximum value. However, if we look at the response of the basal thermocouple in Figure $\mathrm{C} 2$, the time required to reach steady state is small compared to the time for which the base is in a state of thermal equilibrium. If the basal steadystate lasts for a minute or more, as was assumed in the model, then the heat flow conditions imposed in the model closely resemble the actual field process. This is further supported by the times it takes to attain steady state in the model and in Figure C2, which are within a factor of two of each other.

\section{Vertical temperature profile}

For this comparison, the coordinates of the nodes in the finite element mesh were selected by the apparent locations of the thermocouples in the $\mathrm{DH}$ ski. Both Figures $\mathrm{C} 9$ and 14 show the phase-lagged, amplitude-dampened response of thermocouples located above the frictional heat source. It is hard to decide just how closely to compare thermocouples $2 \mathrm{a} 02$ and na02 because the times of frictional heating in the field and computer runs were quite different. While the run in Figure C9 lasted about 30 seconds, the simulated run depicted in $\mathrm{Fi}$ gure 14 lasted for over 3 minutes. Nevertheless, the general characteristics of these two profiles are similar.

\section{Simplifications of the computer model}

From the data collected in the field, we assumed that the weight of a downhill skier is not evenly distributed across the width of the ski, but is applied more to the inside edge. This results in more heat generation near the edge of the ski, which was not taken into account in the computer model. The prevailing philosophy is that it is desirable to have the ski flat on the snow so that meltwater can be evenly generated across the entire width of the ski. Therefore, heat was generated evenly across the base of the ski in the finite element simulation. However, this hindered comparisons of basal heat flow between the model and the field data.

Also, heat generation in the model was not intermittent, as it was in the field because of changes in speed and load. Because of the randomness of these variations in real ski runs, we decided that incorporating these effects would complicate the analysis too much.

\section{CONCLUSIONS}

It was encouraging to have obtained such a large thermal response from frictional heating at the base of both test skis. We initially thought that the response of frictional heat generation might be lost in the noise of the data acquisition system. Instead, the large thermal response has allowed us to characterize the nature of heat generation and heat flow, and helps us understand the coefficient of kinetic friction. Clearly, some of McConica's (1950) ideas of snow friction have been disproved and some ideas of Bowden and Hughes (1939) have been affirmed.

At the outset of this investigation, we hoped that simple, but careful tests of sliders passing over snow could provide meaningful, quantitative results that could be used totest the accuracy of the temperature rises predicted by theory. The theory might then be more useful in quantifying friction under known ambient conditions. However, because of the highly varying conditions that existed in the ski tests, it was difficult to control the parameters affecting the rate of frictional heating. These included the speed and the weight acting on the slider. Although this detracted from the quantitative results, the qualitative analysis gives us some insight into how the frictional heat is distributed and supports existing ideas about the meltwater layer.

The field results support the following conclusions:

1. The formation of a discontinuous meltwater layer is suggested by the steady-state temperature reached at the base of the ski. This temperature wasconsistently close to, but less than, the melting temperature of the snow. There appears to be an upper limit to the basal temperature, which is determined by some combination of the fractional area in contact and the melting temperature.

2. The thermal response is dependent on the ambient temperature of the snow. This suggests that more meltwater is present at higher ambient temperatures, thus the lower friction.

3. The heat generated by friction at the interface is sensitive to the ambient snow temperature, the load and the speed of the slider.

4. The distribution of frictional heating is sensitive to the style of skiing and the hardness of the snow surface. The heat generation is more uniformly distributed if the snow is soft and can conform to the shape of the ski. The heating is concentrated under the skier when the snow is hard. 
5. The steady-state temperature of the base of a ski appears to be independent of the speed, probably because the average temperature at the base is determined by the melting temperature and the contact area, even if the heat production increases.

6. When in a tuck position, a skier's weight is concentrated on the inside edge. This result shows that the ski is not flat on the snow even when the skier perceives it as such. Temperature measurements should be used to learn how to correct this uneven distribution so as to reduce friction.

7. The vertical temperature profile exhibits the characteristic phase-lagged, amplitude-dampened response expected when heat is generated at one surface only.

8. Temperature measurements are a powerful tool for examining such things as the effectiveness of waxes and slider designs and should become a standard tool for testing the behavior of skis and other sliders.

The finite element model results support the following conclusions:

1. A large amount of heat flow occurs out the side of the $\mathrm{DH}$ ski because it has the highly conductive aluminum plate. The heat flux along the aluminum plate is about 40 times greater than up through the wood. Considering that the aluminum plate is about one-fortieth as thick as the wood is wide, about the same a mount of heat flows out the aluminum plate as flows up through the wood. Thus, the aluminum plate about doubles the heat loss from the ski. The replacement of this plate with a material of lower thermal cond uctivity but equal stiffness, such as polyoxymethylene, would inhibit the flow of heat away from the frictional interface and increase the supply of meltwater at the base of the ski.

2. The heat flow out the sides of the ski is increased by the steel edge, but not to the same extent as by the aluminum plate. However, the two complement one another in extracting heat from the base of the ski, and the steel edge is very effective at removing heat at the corner itself.

3. The vertical temperature profile exhibits the characteristic phase-lagged, amplitude-dampened response seen in the tests skis, thus showing that both respond to heat at the base.

4. The finite element model is a useful tool for predicting the thermal response of sliders and can be used to predict, in a qualitative way, the frictional characteristics of anything that slides on snow.

\section{LITERATURE CITED}

Akkok, M., C.M.McC. Ettles and S.J. Calabrese (1987) Parameters affecting the kinetic friction of snow. Journal of Tribology, 109: 552-561.

Ambach, W. and B. Mayr (1981) Ski gliding and water film. Cold Regions Science and Technology, 5(1): 59-65.

Bowden, F.P. (1953) Friction on snow and ice. Proceedings of the Royal Society of London, London, Series A217: 462-478.

Bowden, F.P. and T.P. Hughes (1939) The mechanism of sliding on ice and snow. Proccedings of the Royal Society of London, Series A172: 280-298.

Carslaw, H.S. and J.C. Jaeger (1959) Conduction of Heat in Solids. 2nd Ed. London: Oxford University Press.

Colbeck, S.C. (1988) The kinetic friction of snow. Journal of Glaciology, 34(116): 78-86.

Ericksson, R. (1949) Friction of runners on snow and ice. USA Snow, Ice and Permafrost Research Establishment (SIPRE), Translation 44 (USA Cold Regions Research and Engineering Laboratory).

Evans, D.C.B., J.F. Nye and K.J. Cheeseman (1976) The kinetic friction of ice. Proceedings of the Royal Society of London, Series A347: 493-512.

Kays, W.M. (1960) Convective Heat and Mass Transfer. New York: McGraw-Hill.

Glovsky,R.P. (1982) Development and application of THERMAP: A Finite Element Method (FEM) computer program for predicting the temperature distribution in sliding systems. M.E. Thesis, Thayer School of Engineering, Dartmouth College, Hanover, New Hampshire.

Klein, G.J. (1947) The snow characteristics of aircraft skis. National Research Council of Canada, Aeronautical Report AR-2.

Kuroiwa, D. (1977) The kinetic friction on snow and ice. Journal of Glaciology, 19(81): 141-152.

McConica, T.H. (1950) Sliding on ice and snow: Some considerations of the mechanism. American Ski Company Report.

Oksanen, P. (1983) Friction and adhesion of ice. Espoo: Technical Research Centre of Finland, Laboratory of Structural Engineering, Publication 10, p. 8-16.

Tusima, K. and Z. Yosida (1969) Melting of ice by friction. Hokkaido University, Low Temperature Science Report, Series A: 28-30. 


\section{APPENDIX A: CR 10 DATA ACQUISITION PROGRAMS}

Key strokes

\begin{tabular}{|c|c|c|}
\hline \\
\hline \multicolumn{3}{|c|}{$\begin{array}{l}\text { Example program used to sample } \\
\text { hermocouples in the Blitz ski: } \\
* \quad 1 \text { Access program table } \# 1\end{array}$} \\
\hline \\
\hline \multicolumn{3}{|c|}{$\begin{array}{rrl}\text { A } & 1 & \text { Set } 1 \mathrm{~Hz} \text { sampling frequency } \\
\mathrm{A} & 11 & \begin{array}{l}\text { Record reference junction } \\
\text { temperature }\end{array}\end{array}$} \\
\hline $\mathrm{A}$ & \\
\hline \multicolumn{3}{|l|}{ A } \\
\hline$A$ & 3 & \\
\hline$A$ & 1 & \\
\hline \multicolumn{3}{|l|}{$A$} \\
\hline \multicolumn{3}{|l|}{$A$} \\
\hline$A$ & 14 & $\begin{array}{l}\text { Record thermocouple } \\
\text { temperatures }\end{array}$ \\
\hline A & 5 & \\
\hline A & 1 & \\
\hline \multirow{2}{*}{$\begin{array}{l}\text { A } \\
\text { A }\end{array}$} & 2 & \\
\hline & 1 & \\
\hline $\mathrm{A}$ & 1 & \\
\hline \multirow{2}{*}{$\begin{array}{l}\mathrm{A} \\
\mathrm{A}\end{array}$} & 2 & \\
\hline & 1 & $i$ \\
\hline A & 0 & \\
\hline \multirow{2}{*}{$\begin{array}{l}\mathrm{A} \\
\mathrm{A}\end{array}$} & 86 & Move all values to final memory \\
\hline & 10 & \\
\hline A & 70 & $\begin{array}{l}\text { Place all values in storage module } \\
\text { memory }\end{array}$ \\
\hline A & 5 & \\
\hline \multirow{2}{*}{$\begin{array}{l}\text { A } \\
\text { A }\end{array}$} & 2 & \\
\hline & 96 & \\
\hline \multirow{2}{*}{$\begin{array}{l}\text { A } \\
*\end{array}$} & 71 & \\
\hline & 0 & Compile and run program \\
\hline
\end{tabular}

Example program to sample thermocouples in the DH Ski:

* A Access input number address

39 A Set number of inputs to 39

* 1 Access program table \#1

A 2 Set $0.5 \mathrm{~Hz}$ sampling frequency

A 11 Record reference junction temperature

\section{Key strokes}

Comments
A 9951
A 9999
A 87
A 0
A 32
A $\quad 86$
A $\quad 76$
A 14

A 1

A 1

A 2

A 1

A 1

A 2-

A 1

A 0

A. 95

A 20

A 9990

A 9999

A 14 Record thermocouple temperatures connected to wiring panel

A 4

A 1

A 3

A 1

A 1

A 36

A 1

A 0

A $\quad 86$

A 10

A 70

Move all values to final memory

A 39

A $\quad 2$

A 96

A 71

* 0 Compile and run program

Keystrokes used to manipulate data:

* 6 Observe real time measurements

* 7 Observe measurements sent to storage module memory

* 9 Placefile marks and/orerase data in storage module memory. 
APPENDIX B:THERMOCOUPLE AND MATERIAL CONFIGURATIONS OF THE SKIS

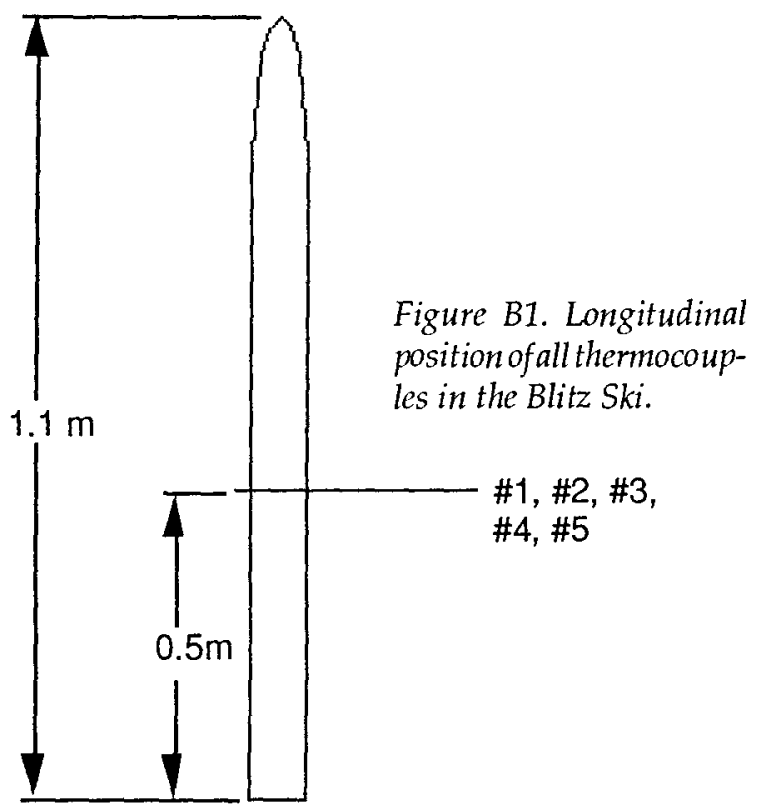

Figure B2. Vertical and transverse locations of thermocouples fortest runs Field11.dat through Field75.dat, FieldA1.dat through FieldA35.dat, and SKI-E1.dat through SKI-E9.dat with the Blitz Ski.
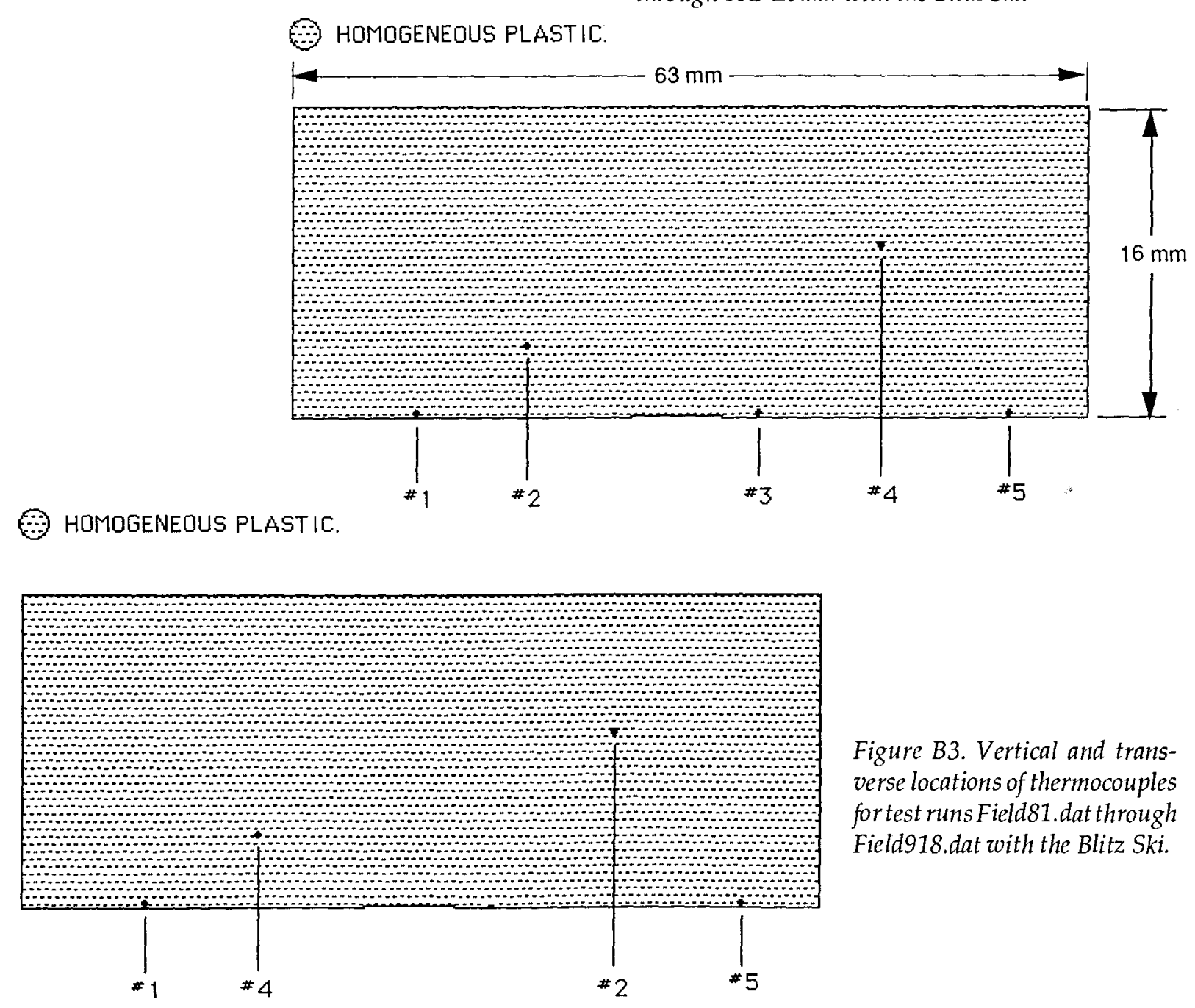

Figure B3. Vertical and transverse locations of thermocouples fortest runs Field81. dat through Field918.dat with the Blitz Ski. 


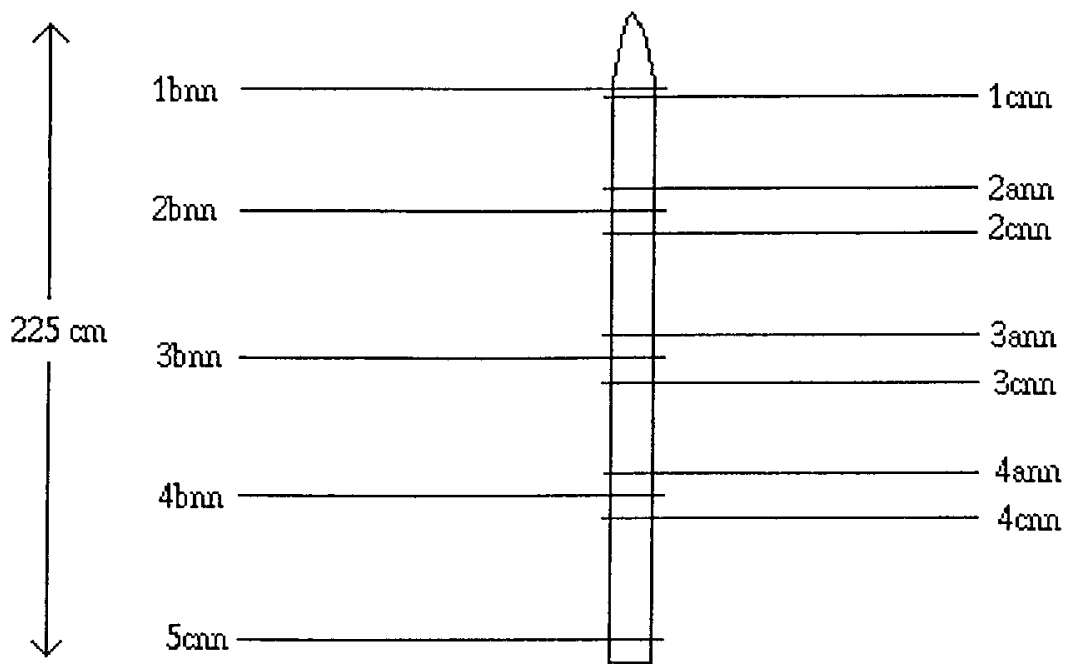

Figure B4. Longitudinal position of all thermocouples in the DH Ski.
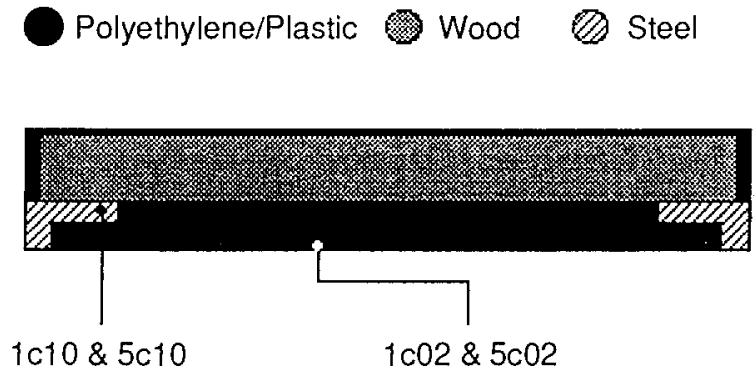

Figure B5. Location of base and edge thermocouples at the front and rear of the DH ski.

(II) Plastic $\bigcirc$ Steel $\bigcirc$ Aluminum $\bigcirc$ Air

Polyethylene (D) Fiberglass Wood

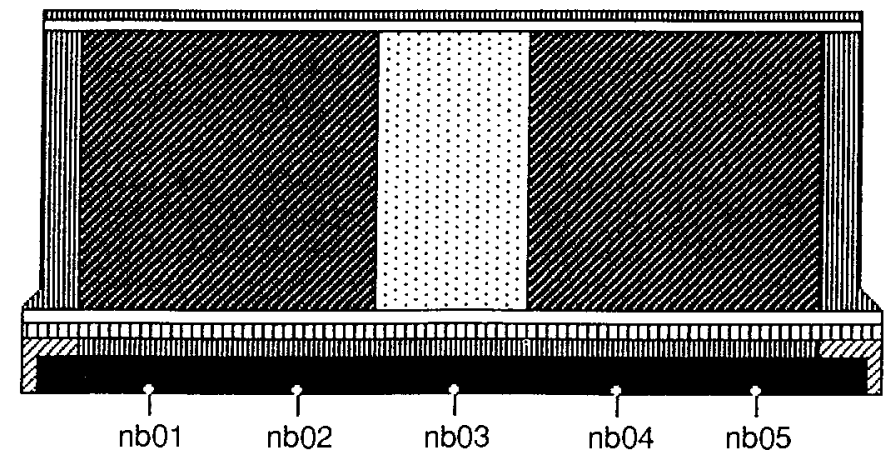

Figure B6. Transverse profile of the basal thermocouples located in the 2bnn, 3bnn and $4 b n n$ longitudinal positions in the DH ski. 
(10) Plastic $\oslash$ Steel $\bigcirc$ Aluminum $\bigcirc$ Air

Polyethylene (D) Fiberglass Wood

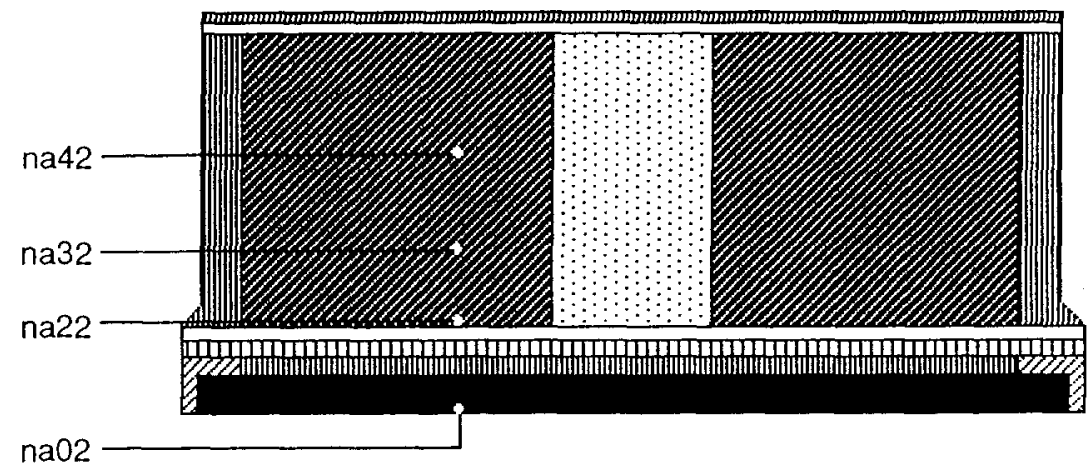

Fignre B7. Vertical profile of the thermocouples located in the 2ann, 3ann and 4ann longitudinal positions in the DH ski.

(1I) Plastic $\oslash$ Steel $\bigcirc$ Aluminum $\oslash$ Air

Polyethylene (D) Fiberglass Wood

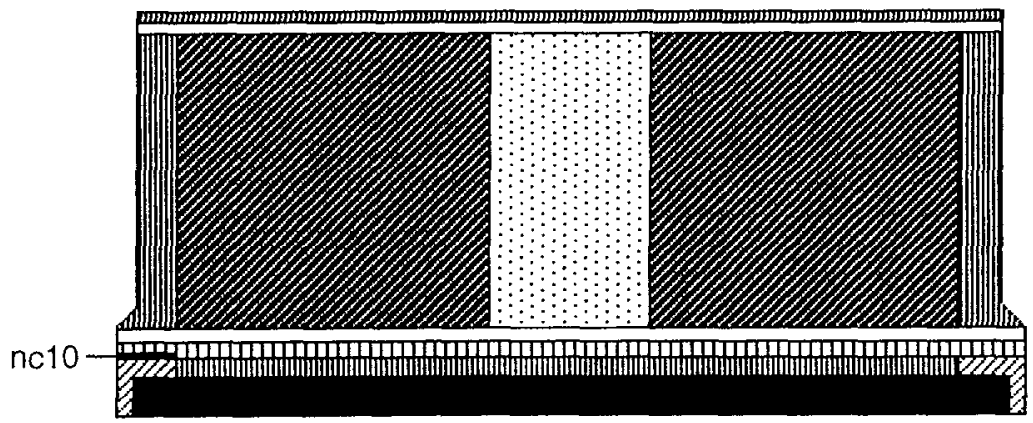

Figure B8. Position of the edge thermocouples located in the $2 \mathrm{cmn}, 3 \mathrm{cum}$ and 4 cnn longitudinal positions in the DH ski. 


\section{APPENDIX C: TEMPERATURE VERSUS TIME PLOTS FROM THE FIELD DATA}

Samples of the temperature measurements are given here. All of the curves have been smoothed with a $0.5-\mathrm{Hz}$ cut-off frequency. The initial temperature at the base of the ski is taken as the ambient temperature. The test run and snow conditions are described briefly. The start of motion is indi- cated by $A$ and the stopping point by $B$. The thermocouples are indicated by number; the location of each thermocouple in the ski is shown in Appendix $B$. The ski can be identified by the number of the thermocouple.

Figure C1. File name: Field 3A.dat. Ambient temperature: $-0.25^{\circ} \mathrm{C}$. Maximuni speed: $\approx 7 \mathrm{~m} / \mathrm{s}$. Run description: Parallel down short, gentle incline with load of $\approx N / 2$. Snow condition: Soft, fresh snow.

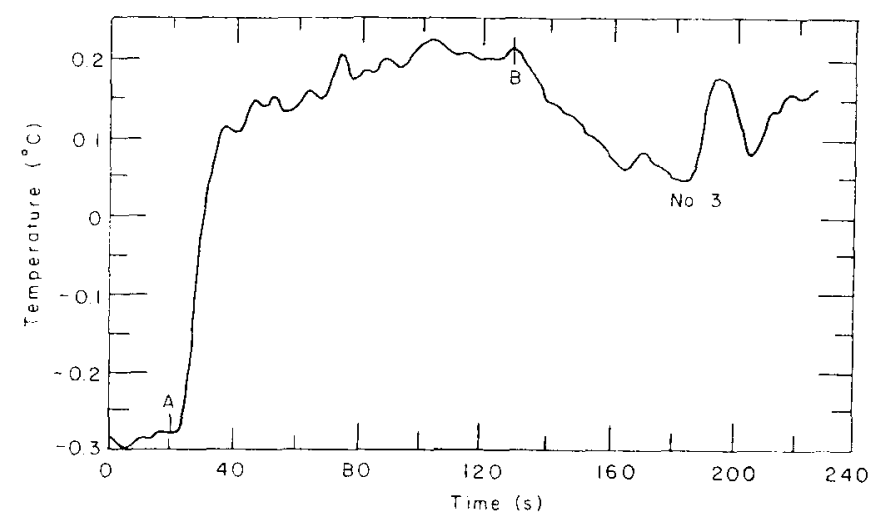

Figure C2. File name: Field 5C.dat. Ambient temperature: $-4.8^{\circ} \mathrm{C}$. Maximum speed: $\approx 9 \mathrm{~m} / \mathrm{s}$. Rundescription: Parallel down short, gentle incline with load of $=\mathrm{N} / 2$. Snow condition: Hard, old, dry snow.

Figure C3. File name:Ski-E5.dat. Ambient temperature: $-3.4^{\circ} \mathrm{C}$. Maximum speed: $\approx 11 \mathrm{~m} / \mathrm{s}$. Run description: Parallel down short, steep incline with load of $\approx 3 \mathrm{~N} / 4$. Snow condition: Soft, fresh snow.
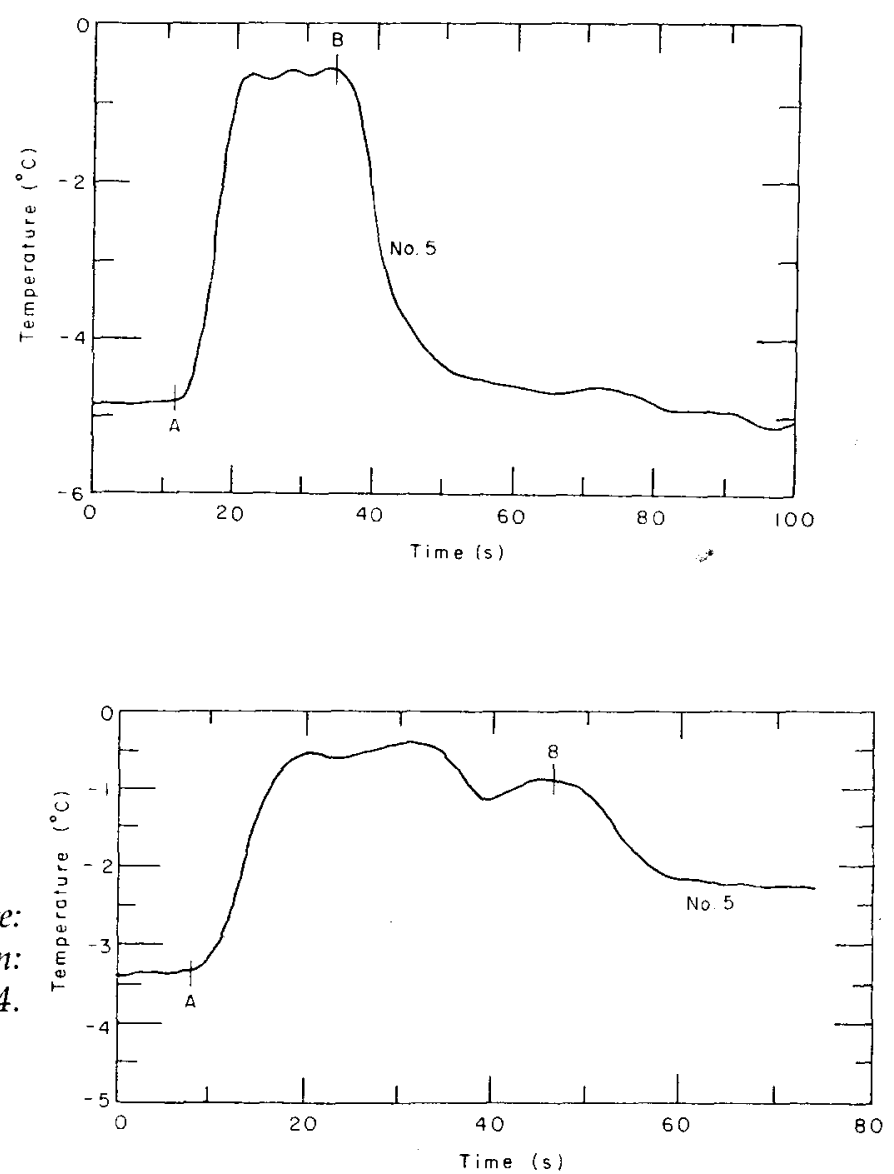

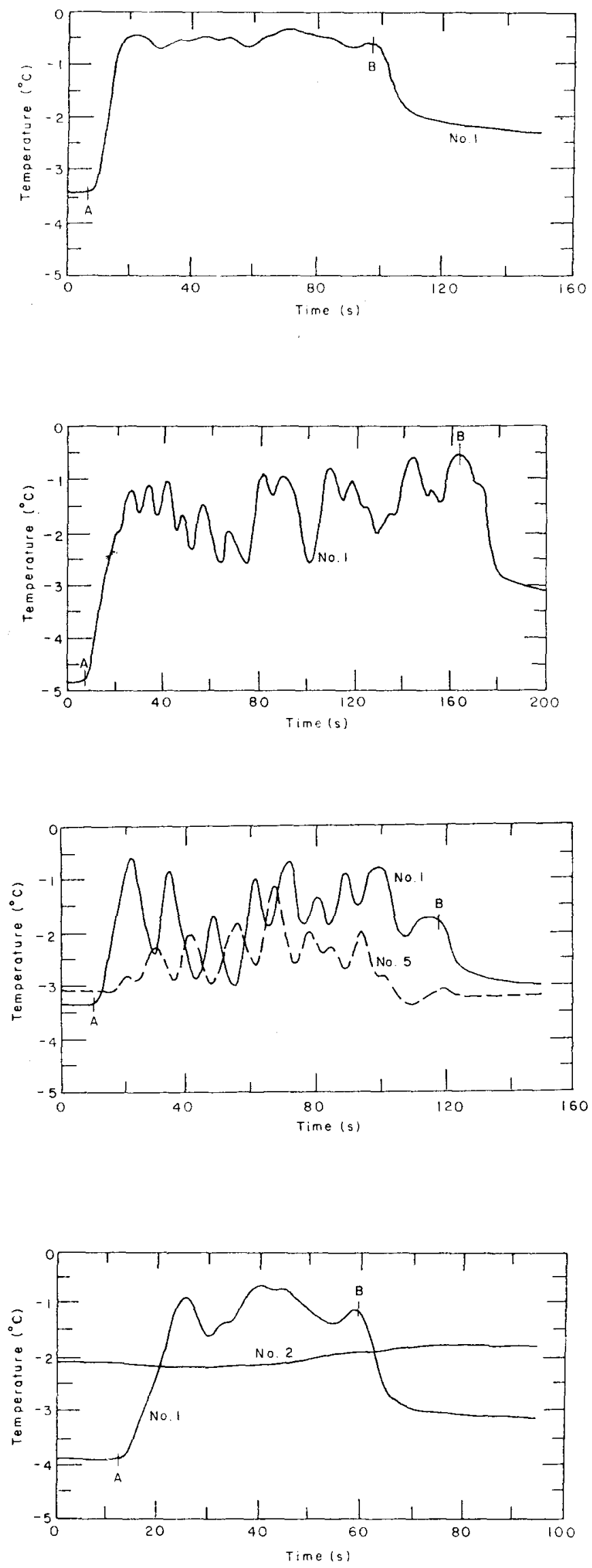

Figure C4. File name: Ski-E9.dat. Ambient tenterature: $-3.5^{\circ} \mathrm{C}$. Maximum speed: $8 \mathrm{~m} / \mathrm{s}$. Run description: Parallel down long, gentle incline with lond of $\approx$ N/2. Snow condition: Soft, fresh snow.

Figure C5. File name: Ski-E6.dat. Ambient temperature: $-4.75^{\circ} \mathrm{C}$. Maximum speed: $\approx 9 \mathrm{~m} / \mathrm{s}$. Run description: Simulation of a downhill run. Time of run $\Rightarrow 75$ seconds. Snow condition: Soft, fresh snow.

Figure C6. File name: Ski-E2.dat. Ambient temperature: $-3.2^{\circ} \mathrm{C}$. Maximum speed: $\approx 6 \mathrm{~m} / \mathrm{s}$. Run description: Wide, smooth turns. Snow condition: Soft, fresh snow.

Figure C7. File name: Ski-E3.dat. Ambient temperature: $-3.9^{\circ} \mathrm{C}$. Maximum speed: $\approx 12 \mathrm{~m} / \mathrm{s}$. Rum description: Parallel down short, steep incline with load of $\approx \mathrm{N} / 2$. Snow condition: Soft, fresh snow. 
Figure CS. File nane: Field 410.dat. Ambient temperature: $-9.5^{\circ} \mathrm{C}$. Maximum speed: $\approx 6 \mathrm{~m} / \mathrm{s}$. Rundescription: Parallel down short, gentle incline with load of $\approx \mathrm{N}$. Snow condition: Dry, packed natural snow.

Figure C9. File name: Field C4D.dat. Ambient temperature: $-1.8^{\circ} \mathrm{C}$. Maximum speed: $\approx 9 \mathrm{~m} / \mathrm{s}$. Run description: Parallel down short, gentle incline with load of $\approx$ N/2. Snow condition: Soft, fresh snow.

Figure C10. File nane: Field S3 dat. Ambient temperature:-1. $8^{\circ} \mathrm{C}$. Maximum sped: $\approx 2 \mathrm{~m} / \mathrm{s}$. Rundescription: Parallel uphill, varying load every 10 seconds. Snow condition: Dry, hard-packed natural snow.

Figure C11. File name: Field B4A.dat. Ambient temperature: $-10^{\circ} \mathrm{C}$. Maximum speed: $\approx 10 \mathrm{~m} / \mathrm{s}$. Run description: Parallel down short, gentle incline with load of $\approx \mathrm{N} / 2$. Snow condition: Dry, hard-packed natural snow.
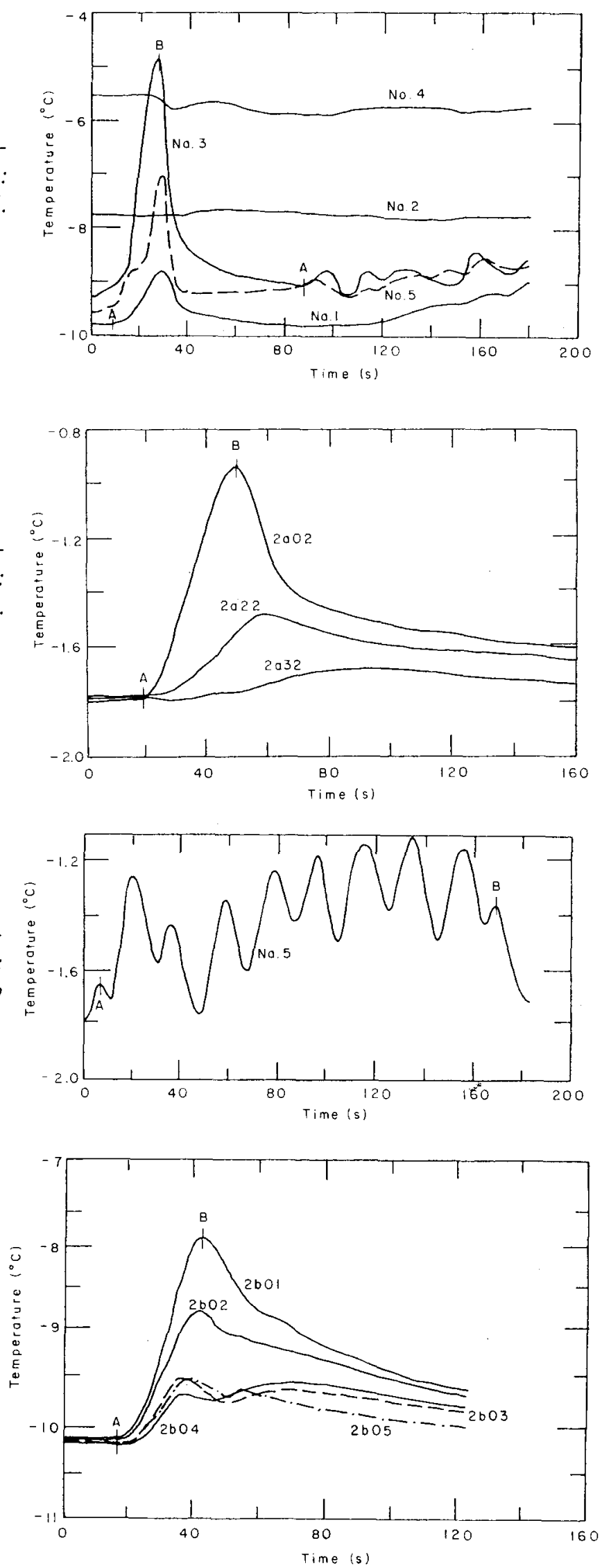

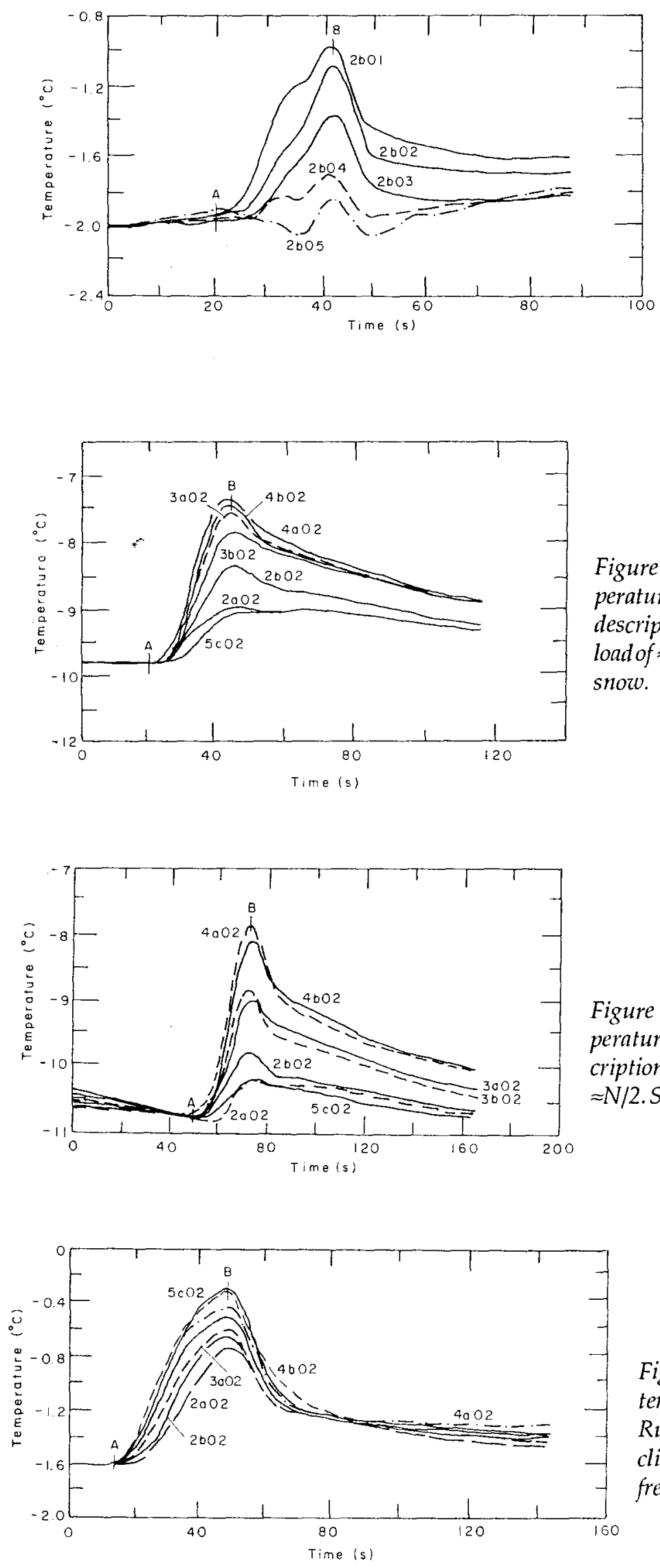

Figure C12. File name: Field C2A.dat. Ambient temperature: $-2.0^{\circ} \mathrm{C}$. Maximum speed: $\approx 9 \mathrm{~m} / \mathrm{s}$. Rundescription:Parallel down short, gentle incline with load of $\approx \mathrm{N} / 2$. Snow condition: Soft, fresh snow.
Figure C13. File name: Field B4*.dat. Ambient temperature: $-9.0^{\circ} \mathrm{C}$. Maximum speed: $\approx 10 \mathrm{~m} / \mathrm{s}$. Run description: Parallel down short, gentle incline with load of $\approx \mathrm{N} / 2$. Snow condition:Dry, hard-packed natural snow.

Figure C14. File name: Field B10*.dat. Ambient temperature: $-11.0^{\circ} \mathrm{C}$. Maximum speed: $\approx 10 \mathrm{~m} / \mathrm{s}$. Run description: Parallel down short, gentle incline withload of $\approx N / 2$. Snowcondition:Dry, hard-packed natural snow.

Figure C15. File name: Field C4*.dat. Ambient temperature: $-1.4^{\circ} \mathrm{C}$. Maximum speed: $\approx 9 \mathrm{~m} / \mathrm{s}$. Run description: Parallel down short, gentle incline with load of $\approx \mathrm{N} / 2$. Snow condition: Soft, fresh snow. 
Figure C16. File name: Field $\mathrm{C} 10^{*}$.dat. Ambient temperature: $-1.5^{\circ} \mathrm{C}$. Maximum speed: $\approx 9 \mathrm{~m} / \mathrm{s}$. Run description: Parallel down short, gentle incline with load of $\approx \mathrm{N} / 2$. Snow condition: Soft, fresh snow.

Figure C17. File name: Field AA.dat. Ambient temperature: $-9.8^{\circ} \mathrm{C}$. Maximum speed: $\approx 6 \mathrm{~m} / \mathrm{s}$. Rundescription: Parallel down short, gentle incline with load of $\approx$ N. Snowcondition:Dry, hard-packed natural snow.

Figure C18. File name: Field A35.dat. Ambient temperature: $-6.7^{\circ} \mathrm{C}$. Maximum speed: $\approx 6 \mathrm{~m} / \mathrm{s}$. Run description: Parallel down short, gentle incline woith load of $\approx$ N. Snow condition: Dry, hard-packed natural snow.
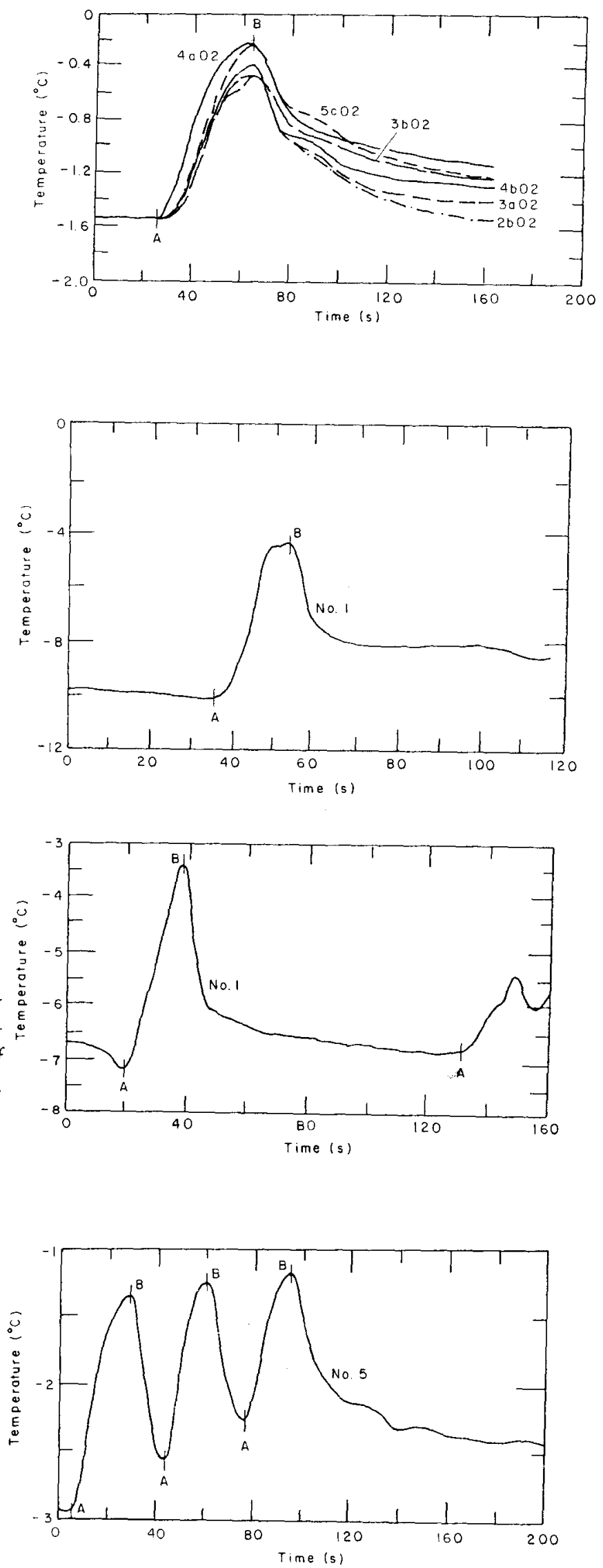

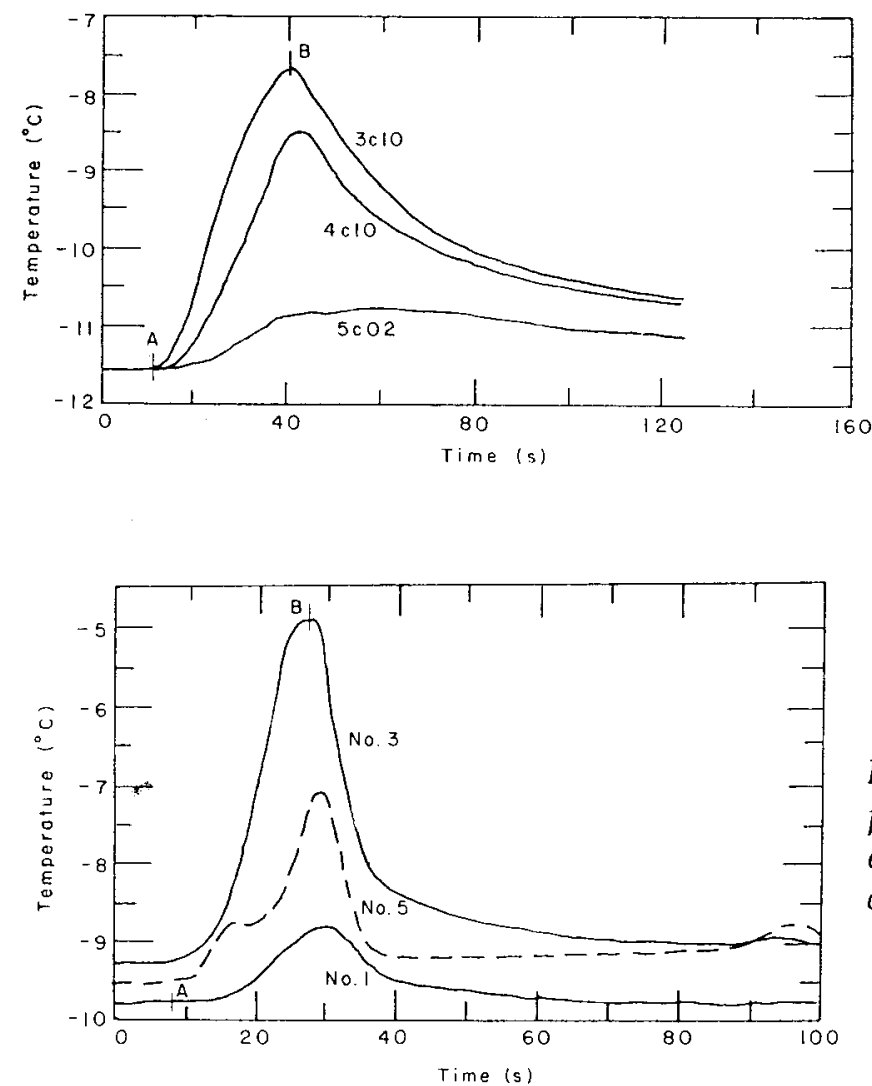

Figure C20. File name: Field B4G.dat. Ambient temperature: $-11.6^{\circ} \mathrm{C}$. Maxinum speed: $\approx 10 \mathrm{~m} / \mathrm{s}$. Run description: Parallel down short, gentle incline with load of $\approx N / 2$. Snow condition: Dry, hardpacked natural snow.

Figure C21. File name: Field 410.dat. Ambient temperature: $-9.5^{\circ} \mathrm{C}$. Maxinum speed: $\approx 6 \mathrm{~m} / \mathrm{s}$. Run description: Parallel down short, gentle incline withlond of $\approx N$. Snow condition: Dry, packed nutural siow.

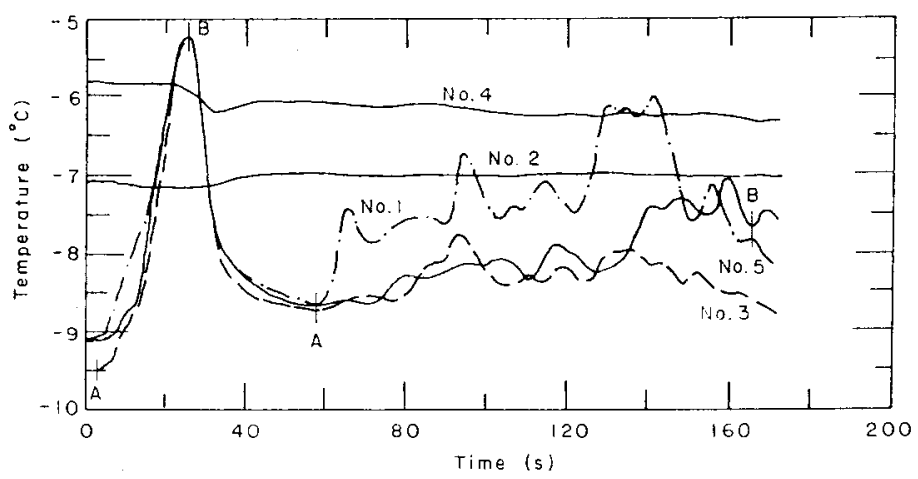

Figure C22. File name: Field A17.dat. Ambient temperature: $-9.3^{\circ} \mathrm{C}$. Maxinum speed: $\approx 6 \mathrm{~m} / \mathrm{s}$. Run description: Parallel down short, gentle incline with load of $\approx N$, followed by varying load up Poma lift with constant spect of $\approx 2 \mathrm{mi} /$ s. Snow condition: Dry, hard-packed matural snow.

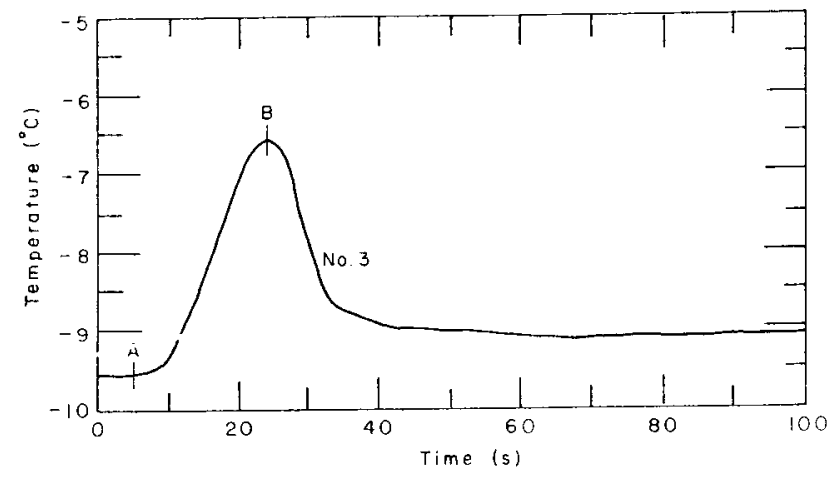

Figure C23. File nane: Field 4A.dat. Ambient temperature: $-9.5^{\circ} \mathrm{C}$. Maxinum speed: $\approx 6 \mathrm{~m} / \mathrm{s}$. Run description: Parallel down short, gentle incline with load of $\approx N / 2$. Snowe condition: Dry, packed natural showe. 
Figure C24. File name: Field 4A.dat (unsmoothed). Ambient temperature: $-9.5^{\circ} \mathrm{C}$. Maximumspeed: $\approx 6$ m/s. Run description: Parallel down short, gentle incline with load of $\approx N / 2$. Snow condition: Dry, packed natural snow.

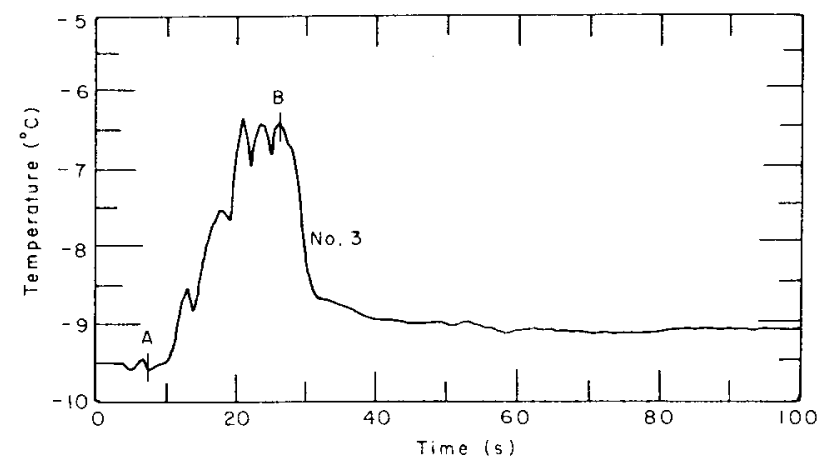




\section{APPENDIX D: PLOTS GENERATED BY THE FINITE ELEMENT COMPUTER MODEL}

The transient response from 5 seconds to steady state for case 1. Parameters: Ambient temperature $T_{0}$ $=-5^{\circ} \mathrm{C}$; convection coefficient: $75 \mathrm{~W} / \mathrm{m}^{2} 0^{\circ} \mathrm{C}$. The magnitude and location of the maximum and minimum temperatures are indicated to the right of the plot.
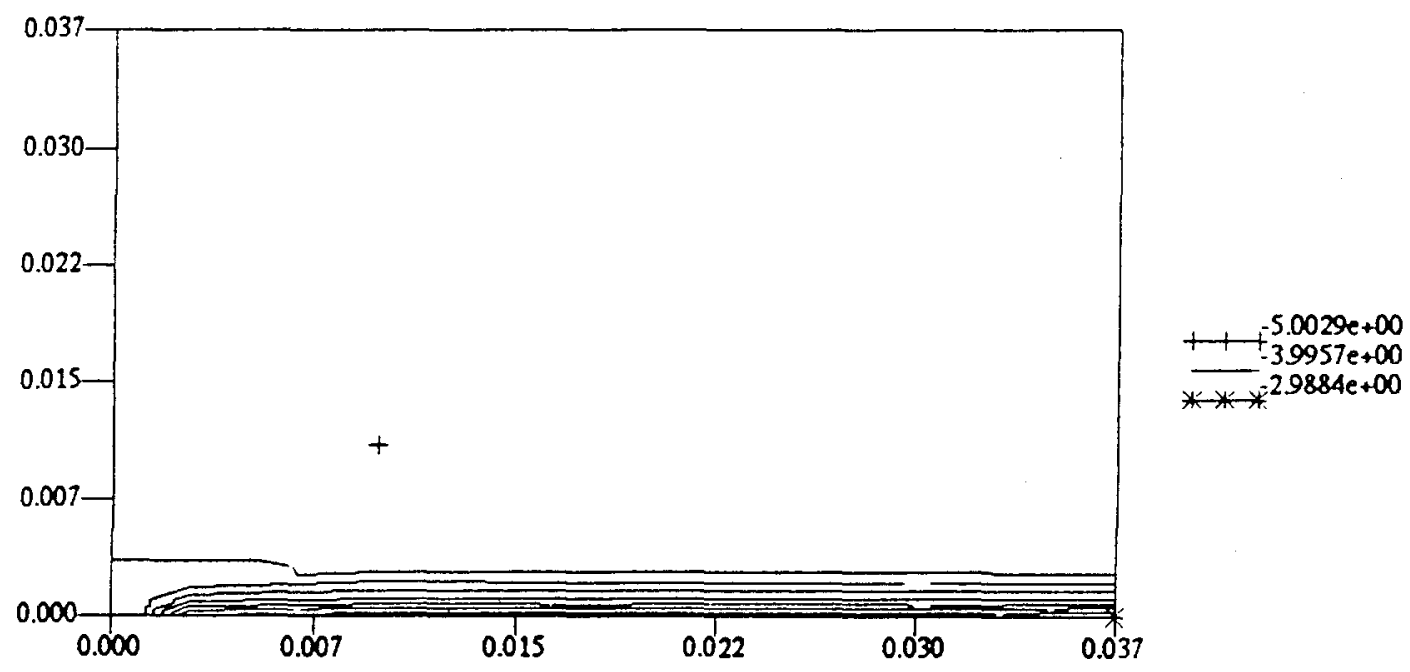

Figure D1. Transient response at 5 seconds.

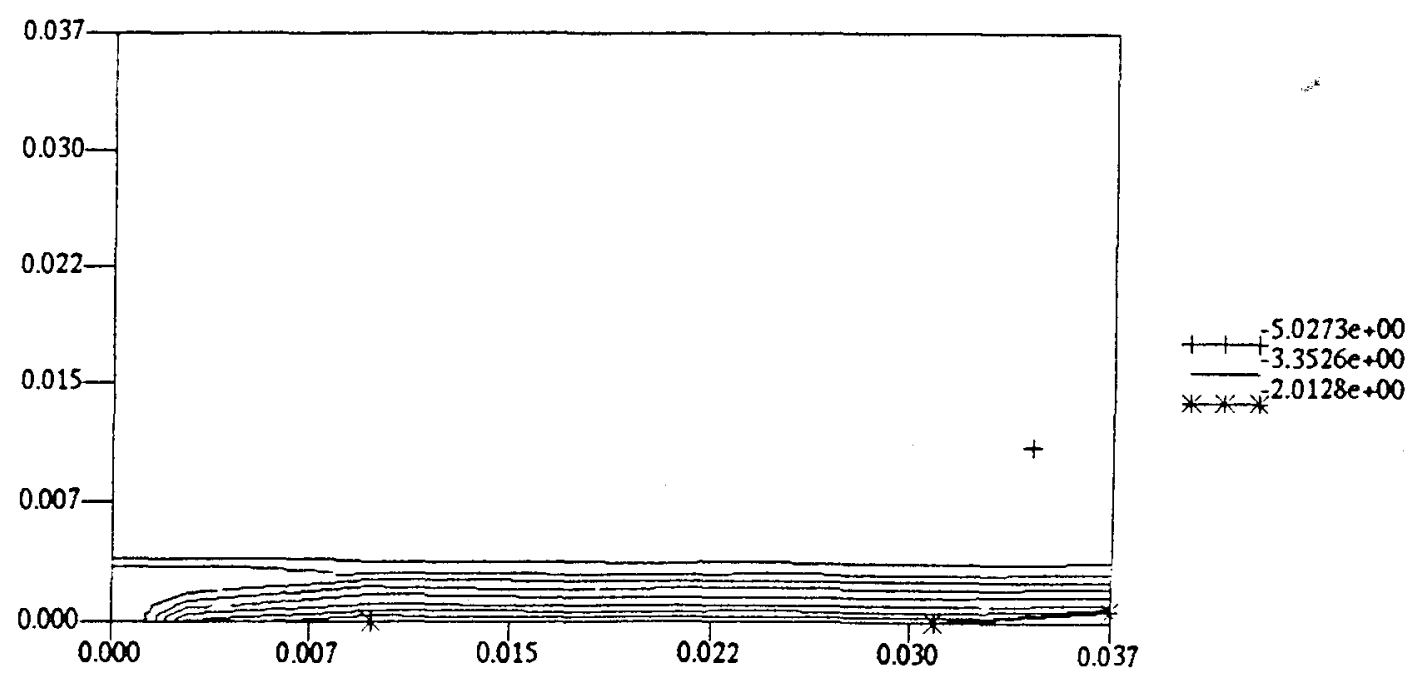

Figure D2. Transient response at 10 seconds. 

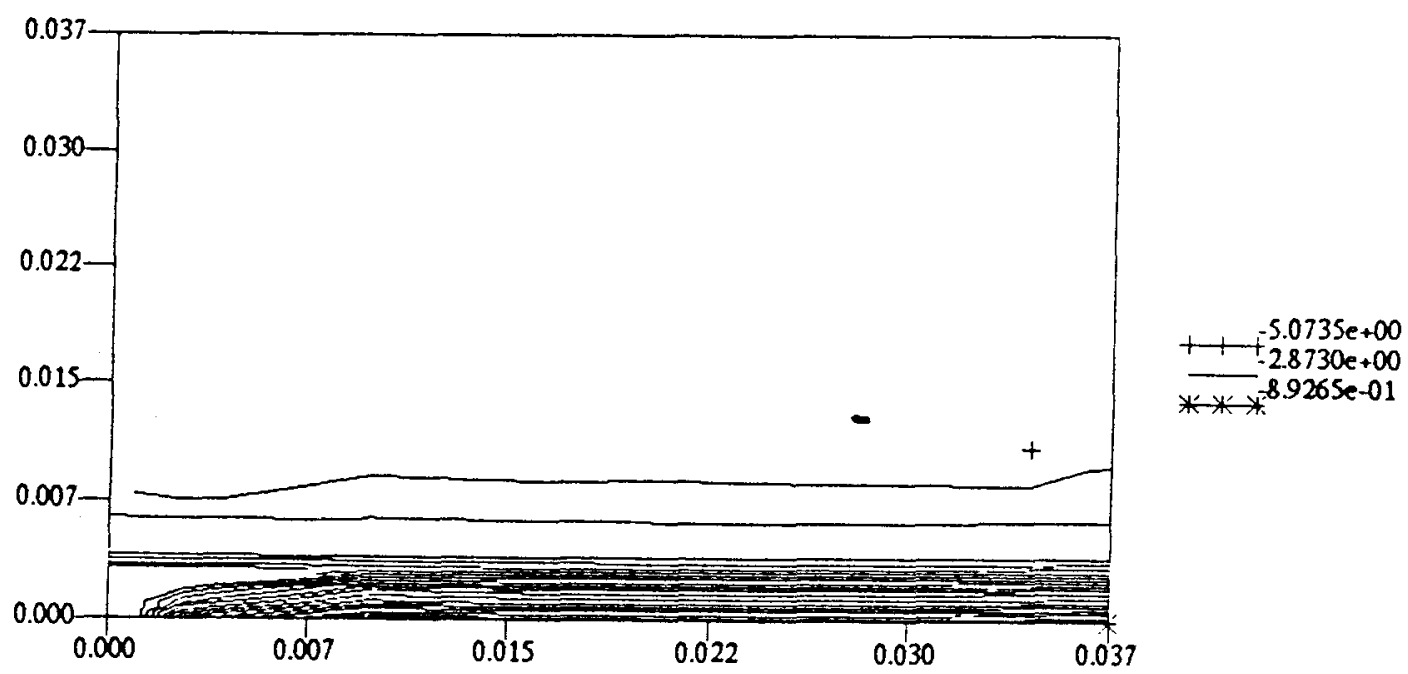

Figure D3. Transient response at 17 seconds.

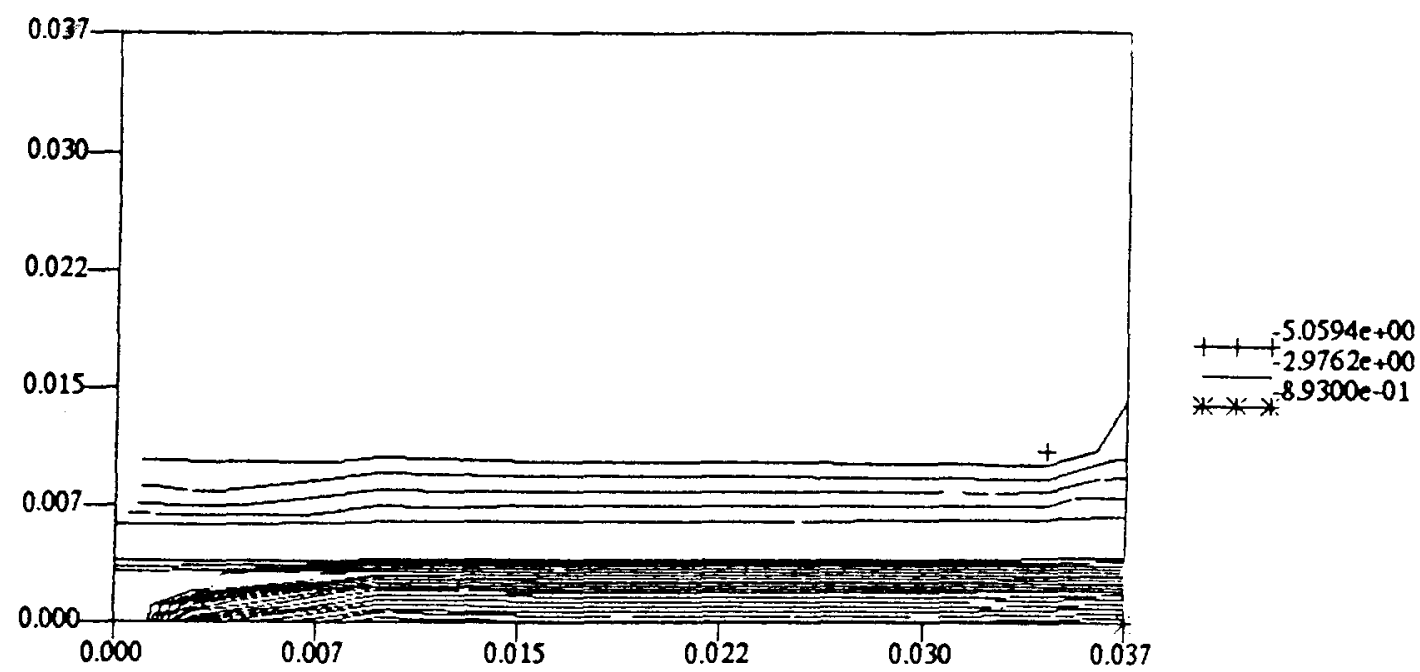

Figure D4. Transient response at 27 seconds.

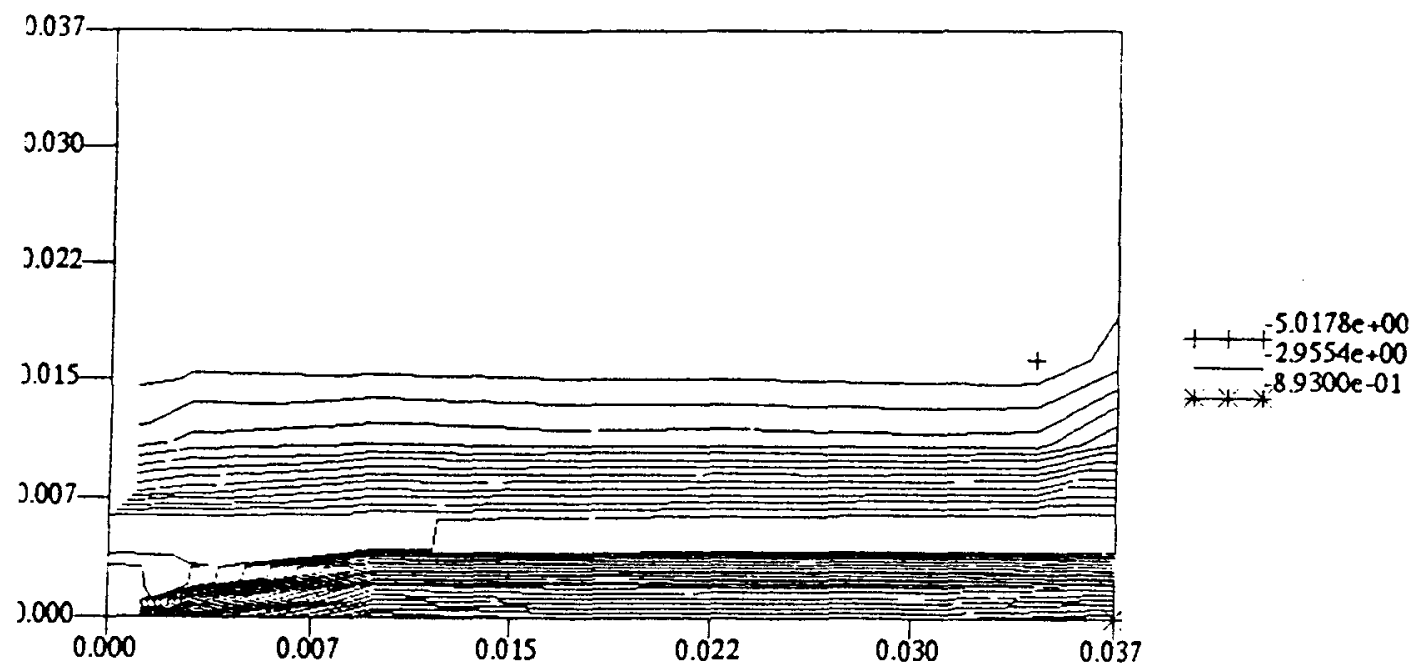

Figure D5. Transient response at 57 seconds. 

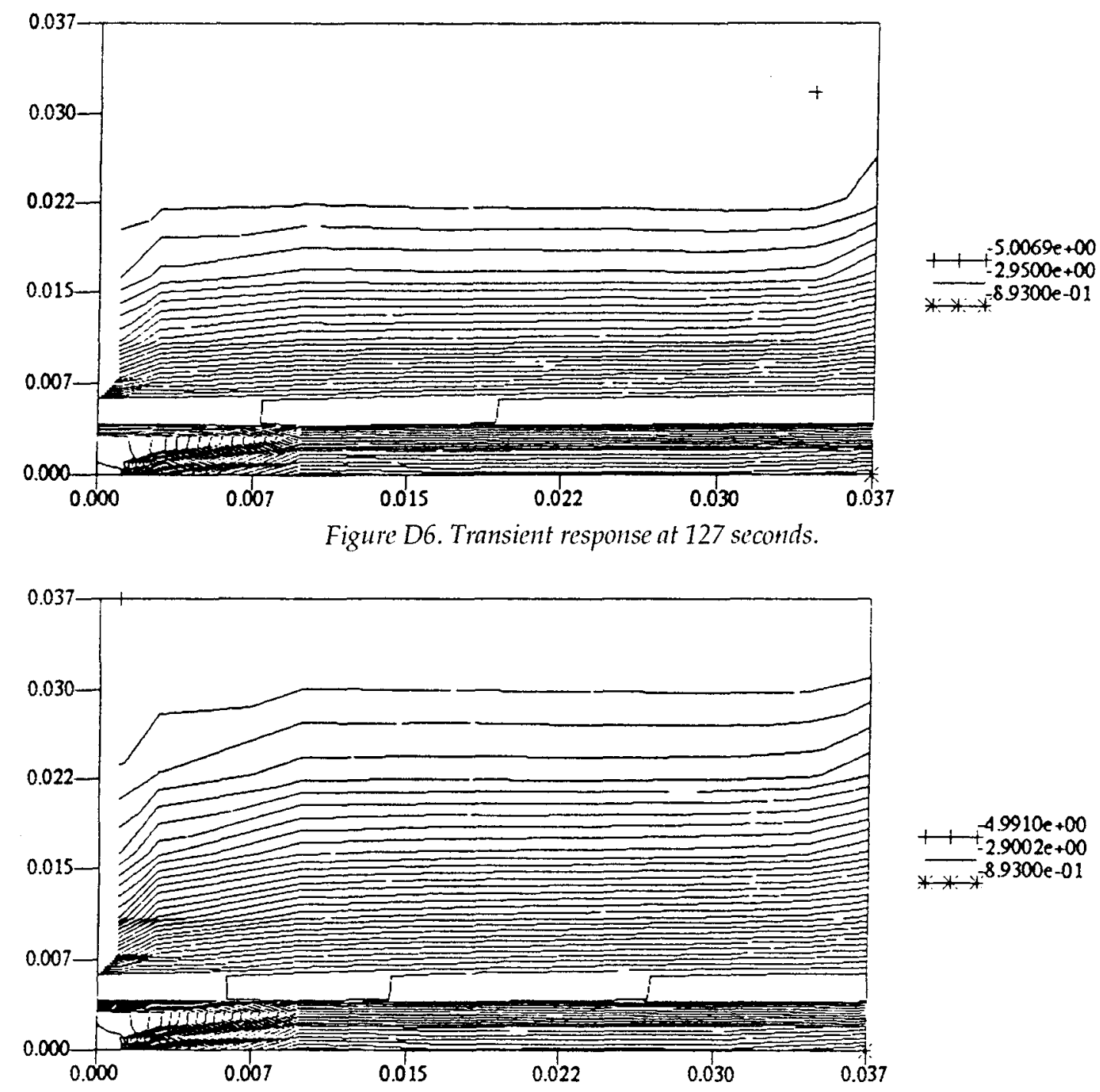

Figure D7. Transient response at 227 seconds.

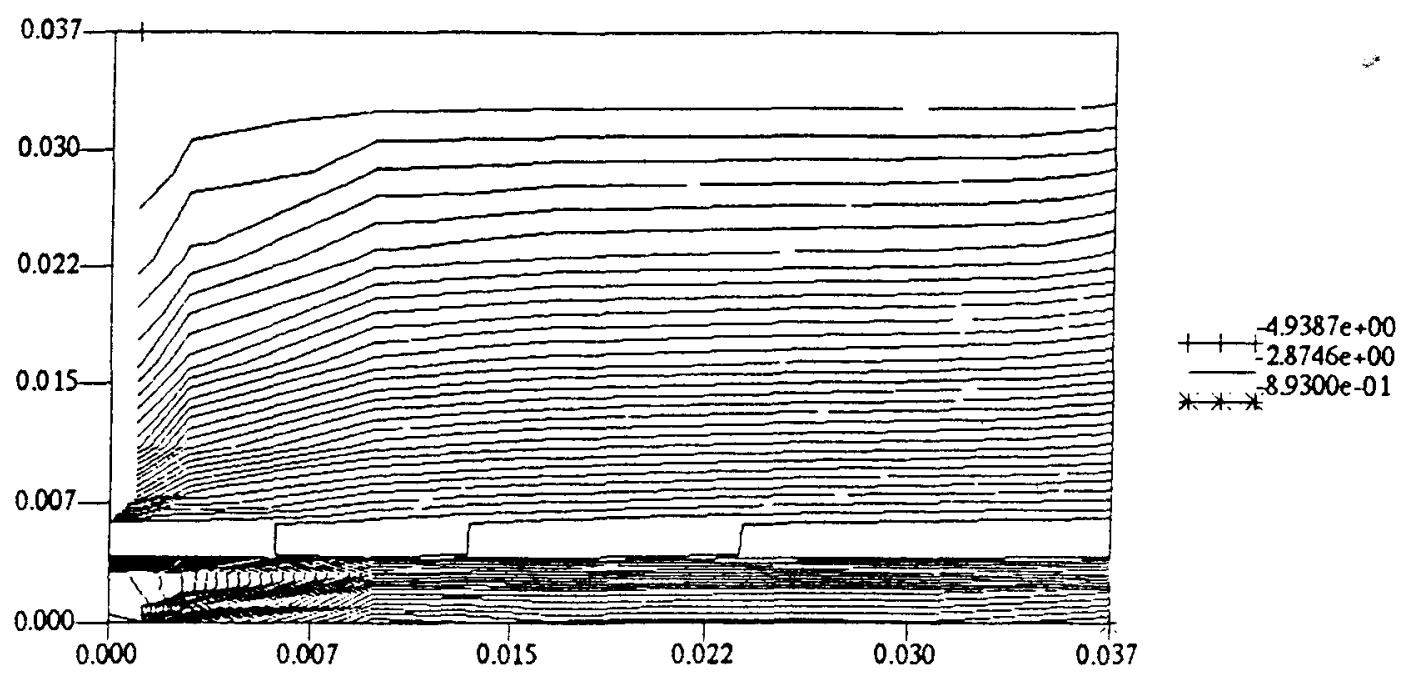

Figure D8. Transient response at 377 seconds. 


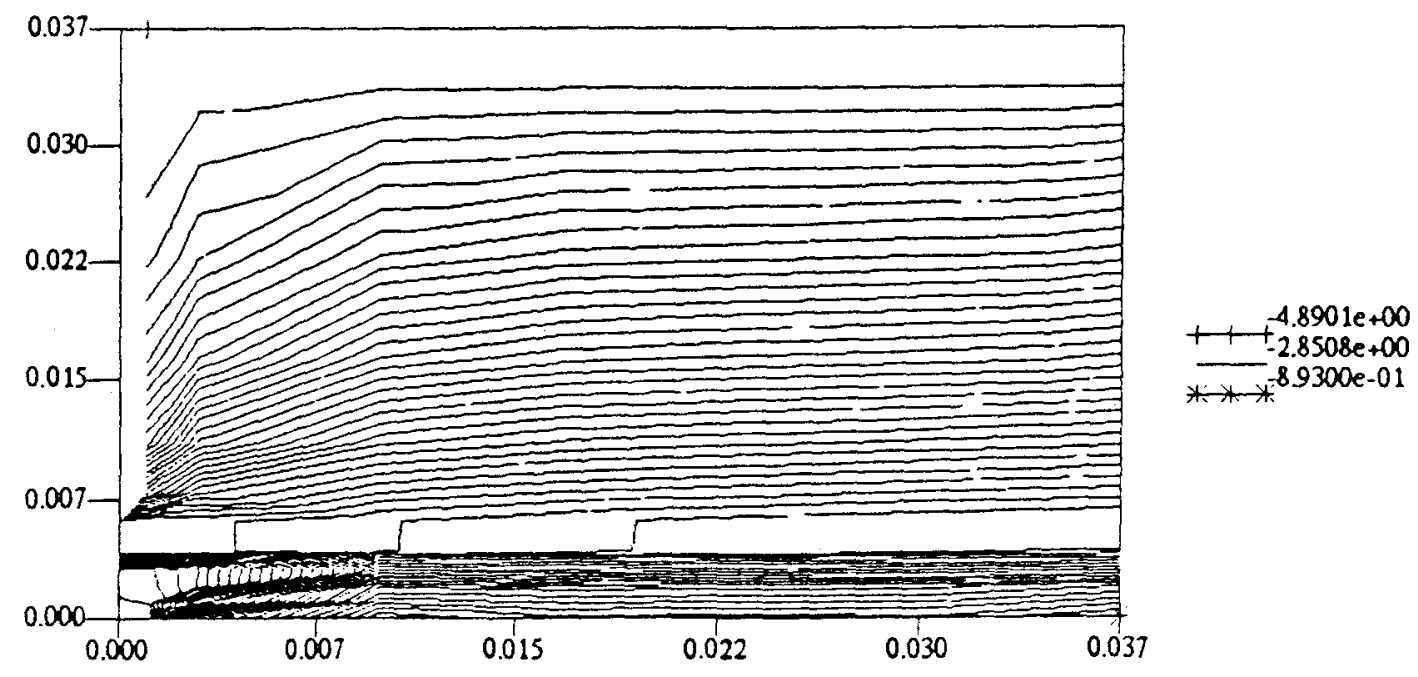

Figure D9. Transient response at 577 seconds.

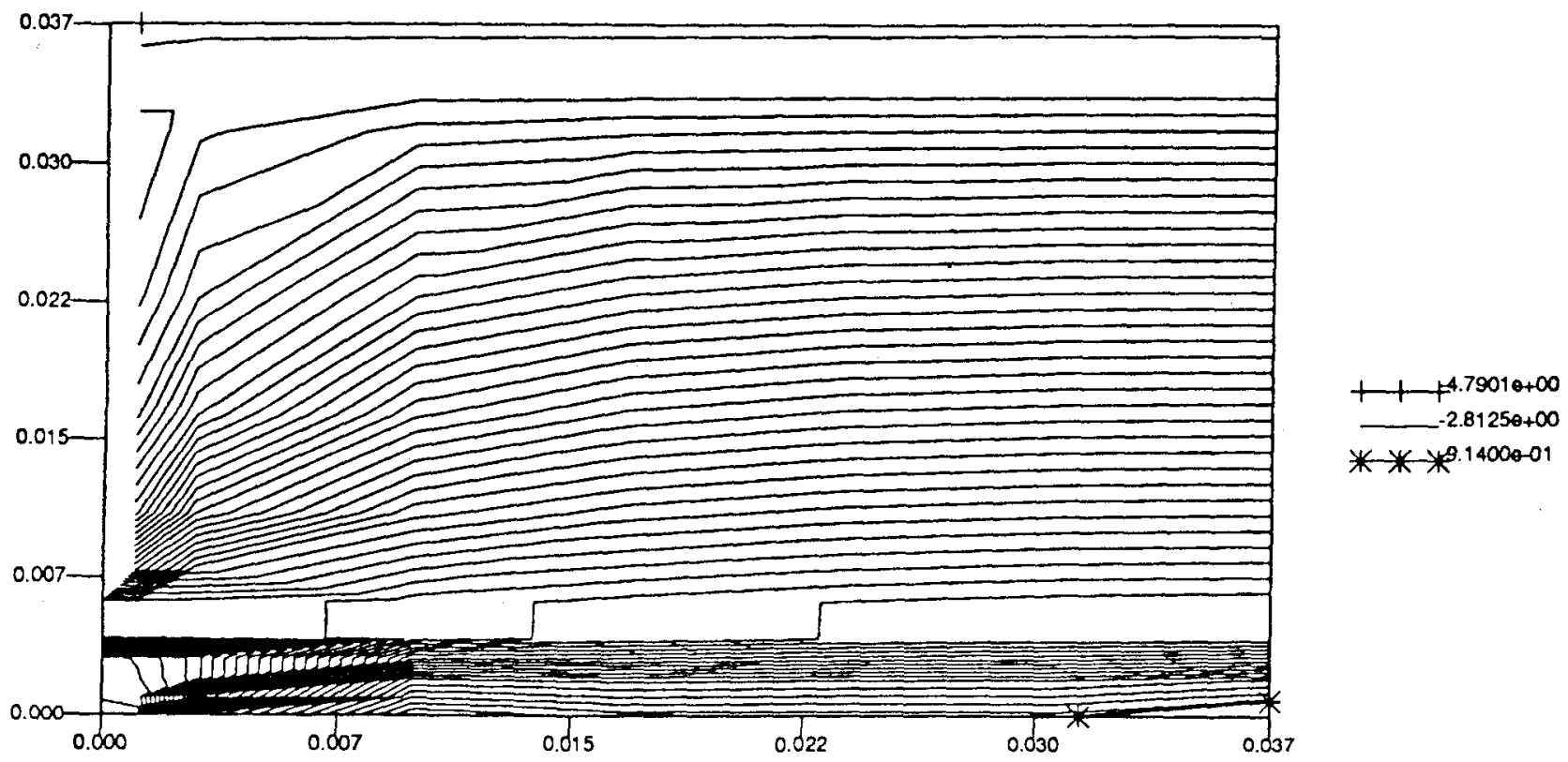

Figure D10. Steady-state response. 